\title{
microRNAs identified in prostate cancer: Correlative studies on response to ionizing radiation
}

Maureen Labbé ${ }^{1}$, Christianne Hoey ${ }^{2,3}$, Jessica Ray ${ }^{2,3}$, Vincent Potiron ${ }^{1,4}$, Stéphane Supiot ${ }^{1,4}$, Stanley K. Liu ${ }^{2,3,5^{*}}$ and Delphine Fradin ${ }^{1 *}$

\begin{abstract}
As the most frequently diagnosed non-skin cancer in men and a leading cause of cancer-related death, understanding the molecular mechanisms that drive treatment resistance in prostate cancer poses a significant clinical need. Radiotherapy is one of the most widely used treatments for prostate cancer, along with surgery, hormone therapy, and chemotherapy. However, inherent radioresistance of tumor cells can reduce local control and ultimately lead to poor patient outcomes, such as recurrence, metastasis and death. The underlying mechanisms of radioresistance have not been fully elucidated, but it has been suggested that miRNAs play a critical role. miRNAs are small non-coding RNAs that regulate gene expression in every signaling pathway of the cell, with one miRNA often having multiple targets. By fine-tuning gene expression, miRNAs are important players in modulating DNA damage response, cell death, tumor aggression and the tumor microenvironment, and can ultimately affect a tumor's response to radiotherapy. Furthermore, much interest has focused on miRNAs found in biofluids and their potential utility in various clinical applications. In this review, we summarize the current knowledge on miRNA deregulation after irradiation and the associated functional outcomes, with a focus on prostate cancer. In addition, we discuss the utility of circulating miRNAs as non-invasive biomarkers to diagnose, predict response to treatment, and prognosticate patient outcomes.
\end{abstract}

Keywords: microRNA, prostate cancer, radiotherapy, radiation resistance, biomarkers

\section{Introduction}

Prostate cancer $(\mathrm{PCa})$ is the second most common cancer and the fifth leading cause of cancer death in men worldwide, with an estimated 1.3 million new cases and 359,000 deaths per year [1]. Currently, treatment options for localized disease are active surveillance, prostatectomy, or radiotherapy, with or without hormone therapy [2,3]. Despite curative radiation regimens, radioresistance and clinical relapse is

\footnotetext{
* Correspondence: Stanley.Liu@sunnybrook.ca; delphine.fradin@inserm.fr ${ }^{2}$ Department of Medical Biophysics, University of Toronto, Toronto, Ontario, Canada

${ }^{1}$ CRCINA, INSERM, Université d'Angers, Université de Nantes, Nantes, France Full list of author information is available at the end of the article
}

reported in numerous cancer types [4-7], including $\mathrm{PCa}$ [8]. Understanding the molecular events that cause radioresistance in $\mathrm{PCa}$ can lead to the development of improved therapies.

Ionizing radiation (IR) induces biological effects in both tumor cells and the surrounding tumor microenvironment (TME) (Fig. . 1). On a cellular level, IR produces DNA damage, both directly from ionization and indirectly by generation of Reactive Oxygen Species (ROS) [9]. DNA damage triggers the DNA Damage Response (DDR) to repair damaged DNA, or induces cell cycle arrest and cell death if repair is not possible [10, 11]. As cell cycle checkpoints are frequently dysregulated in cancer, radiotherapy exploits this vulnerability to produce 


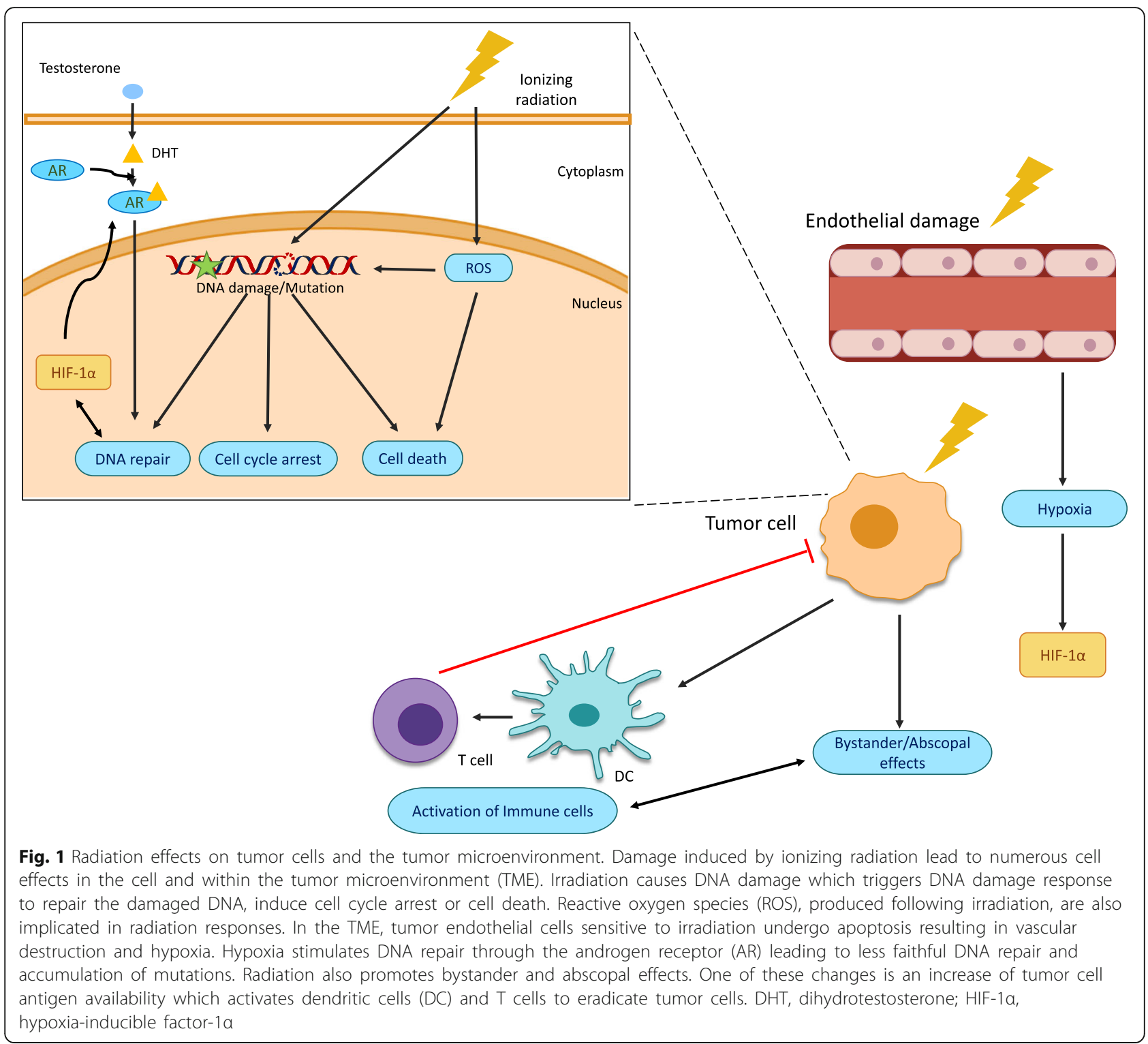

greater unrepaired DNA damage and subsequent cell death within tumor cells. The biological impact of IR is greatly affected by hypoxia within the target site, which influences the amount of DNA damage caused by IRinduced ROS. Hypoxia is a pathological state where the tissue has low levels of oxygen reaching the cells. Under hypoxic conditions, hypoxia-inducible factor $1 \alpha$ (HIF$1 \alpha)$ is stabilized and allows for the transcription of genes involves in tumor survival and progression. Chronic hypoxia has also been demonstrated to impair DNA repair through downregulation of the repair machinery resulting in genomic instability which may select for a more aggressive cancer phenotype [12]. To partly counter the negative impact of a hypoxic TME on IR, a fractionated radiotherapy course is typically employed (i.e., treatments delivered daily over several weeks). This fractionated treatment eliminates the well oxygenated tumor cells, which then allows for hypoxic cells to reoxygenate and become radiosensitive [13-15]. After all, oxygen is the best radiosensitizer due to its role in generating ROS. IR also affects the TME [16], notably by modifying the vasculature large doses of radiation may promote endothelial cell apoptosis [17], and vascular collapse, whereas smaller doses of fractionated IR can promote vascular maturation and improved perfusion [18]. Tumor response to IR can be modulated by other cells through two phenomenon: the bystander effect, where non-irradiated cells are negatively impacted by adjacent irradiated cells; and the abscopal effect where the immune system becomes primed to eradicate tumor cells at sites distant from the irradiated site [19]. Indeed, IR can lead to immunogenic cell death, as immune cells 
utilize antigens generated from damaged tumor cells to activate dendritic cells (DCs) and CD8+ cytotoxic T cells to kill tumor cells [20]. Interestingly, hypoxia promotes transcription of the androgen receptor (AR) expression [21], which is a key moderator of PCa proliferation and survival [22].

Due to this central role of AR in proliferation, survival, and treatment response [23, 24], Androgen Deprivation Therapy (ADT) is commonly used in synergy with RT [25] as a therapy for PCa due to its vital role in PCa progression. Despite the initial response to ADT, most patients develop resistance and progress to a more aggressive form of $\mathrm{PCa}$, referred as Castration-Resistant Prostate Cancer (CRPC). Interestingly, CRPC cells upregulate the expression of AR (notably AR spliced variants leading to constitutively active AR) and overtime acquire radioresistance. AR signaling enhances DNA DSB repair through the non-homologous end-joining (NHEJ) pathway [26], and induces the over-expression of ataxiatelangiectasia mutated (ATM) in CRPC cells [27]. In CRPC cells, including the radioresistant ones, activated CDC42 kinase 1 (Ack1) is over-expressed. Ack1 is a kinase implicated in the phosphorylation of $\mathrm{pTyr}^{267}$-AR, which is critical to androgen-independent AR transactivation and tumor promoting. During this process, $\mathrm{pTyr}^{267}$-AR is recruited to the ATM enhancer to up-regulate ATM, which could lead to radioresistance. It has also been shown that IR can induce expression of AR in a dose-dependent manner, through modulating nuclear translocation and increasing transcriptional activity [28], which may promote radioresistance.

Research into the molecular mechanisms governing radioresistance continues to shed new light onto this important clinical problem. A class of non-coding RNAs (ncRNAs) termed microRNAs (miRNAs) are believed to play a key role in the regulation of radiation response, and their expression has been linked to radioresistance in many cancers [29-33]. Thus, further investigation into the radio-modulating role of miRNAs in $\mathrm{PCa}$ is important. Indeed, altered miRNA expression occurs rapidly after IR [34, 35] and leads to rapid changes in protein levels of the targeted mRNAs. miRNAs are ncRNAs of approximately 19 to 22 nucleotides in length that negatively regulate gene expression at the post-transcriptional level [36]. Association of a miRNA with the protein Argonaute (AGO) forms an RNA-induced silencing complex (RISC), which then binds the mRNA target primarily on the 3'untranslated region (3'UTR) [37], and decreases gene expression via translational repression, mRNA cleavage, or destabilization of the target mRNA [38]. miRNAs have been shown to modulate virtually all cellular processes including cell cycle control, proliferation, and differentiation [39], and can consequently impact the response to radiotherapy through influencing these pathways. Nevertheless, the number of studies on the regulatory mechanisms of miRNA in PCa radioresistance is quite limited, and our understanding of the functional role exerted by these miRNAs is only beginning to be elucidated. Furthermore, there is a significant clinical need to find non-invasive biomarkers to improve the management of $\mathrm{PCa}$, and circulating miRNAs may serve to fulfill this need.

In this review, we will first provide an up-to-date summary of the literature on miRNAs that are influenced by radiotherapy in PCa. We will then examine the role of miRNAs in cellular response to radiation, and discuss the utility of using circulating miRNAs as non-invasive biomarkers.

\section{miRNAs in response to radiotherapy}

It is known that miRNA expression can be modulated by IR. This can occur in PCa cells as well as surrounding cells exposed to radiation treatment [31]. Numerous studies, using Next Generation Sequencing (NGS) or microarray technology, have investigated miRNA expression in cells before and following exposure to IR (Table 1). We observed large differences between studies, including the radiation dose, the technology and methodology used, and perhaps most notably the miRNA expression patterns in cells before IR. Due to these variations, the same miRNA is often identified in the literature as being both up- and down-regulated after irradiation, depending on the study. For example, miR-141 has been shown to be up-regulated in LNCaP cells [49] and down-regulated in 22RV1radioresistant (RR) cells [50]. Interestingly, circulating miR-141 is sometimes up-regulated in PCa patients before treatment when compared with healthy controls [56-58]. A high expression level of miR-141 in human PCa surgical specimens $(n=535)$ is associated with reduced biochemical or clinical failure-free survival [59]. In human PCa cell lines where miR-141 is under-expressed, Liu et al. have recently identified its target by whole-genome RNA sequencing (RNA-seq) such as multiple pro-metastasis genes like CD44, Rho GTPase and enhancer of zeste 2 polycomb repressive complex 2 subunit (EZH2) [60]. These results highlight the contradiction action of miR-141 in PCa and suggest that one miRNA could act as oncomiR or suppressor of tumor in $\mathrm{PCa}$.

Additional prominent IR-responsive miRNAs are members of the let-7 family, whose expression is frequently found to be altered by IR, however, this is not surprising since the mature members of this family are the most abundant among all miRNAs in the cell [40, $41,43]$. The let-7 family is most commonly described as a tumor suppressor family as they inhibit the expression of multiple oncogenes such as KRAS [61] and Myc [62]. 
Table 1 miRNAs dysregulated by irradiation in prostate cancer cells

\begin{tabular}{|c|c|c|c|c|c|c|}
\hline \multicolumn{6}{|c|}{ miRNA after irradiation } & \multirow[t]{2}{*}{ Functional role } \\
\hline Expression & miRNAs & Cell lines & Doses & Methods & $\overline{\text { References }}$ & \\
\hline \multirow[t]{13}{*}{ Increased } & $\begin{array}{l}\text { let-7e, miR-18b miR-92a-1, miR-92a-2, } \\
\text { miR-320a, miR-365-1, miR-365-2 }\end{array}$ & PC-3-RR cells & 2 Gy $\times 45$, fractionnated & NGS & {$[40]$} & - \\
\hline & miR-95 & & & & & Radioresistance [40] \\
\hline & $\begin{array}{l}\text { miR-9, miR-22, miR-25, miR-550a, } \\
\text { miR-548h }\end{array}$ & PC-3 cells & 10 Gy & NGS & [41] & - \\
\hline & miR-30a & & & & & Radiosensitization [42] \\
\hline & let-7 family, miR-34a, miR-146a & PC-3 and LNCaP cells & $\begin{array}{l}0.5 \text { Gy } \times 10,1 \text { Gy x } 10, \\
\text { fractionned }\end{array}$ & microarray & {$[43]$} & - \\
\hline & miR-16 & LNCaP cells & 0.5 or 4 Gy & microarray & {$[44]$} & Radiosenzitization [45] \\
\hline & miR-34c, miR-372, miR-520c, miR-520f & LNCaP cells & 6 Gy & microarray & {$[46]$} & - \\
\hline & miR-449 & & & & & Radiosensitization $[47,48]$ \\
\hline & $\begin{array}{l}\text { miR-9-1, miR-22, miR-24, miR-29b, } \\
\text { miR-141, miR-191, miR-200c }\end{array}$ & LNCaP cells & 6 Gy & microarray & [49] & \\
\hline & miR-30a & & & & & Radiosensitization [42] \\
\hline & $\begin{array}{l}51 \text { miRNAs increased notably } \\
\text { miR-29a, miR-130a, miR-4521 }\end{array}$ & 22RV1-RR compared to 22RV1 cells & $\begin{array}{l}60 \mathrm{~Gy},(2 \mathrm{~Gy} \\
\text { fractioned doses) }\end{array}$ & microarray & {$[50]$} & - \\
\hline & miR-221, miR-222 & & & & & Radioresistance [51] \\
\hline & $\begin{array}{l}\text { miR-34c, miR-154*, miR-379, } \\
\text { miR-383, miR-488 }\end{array}$ & C4-2 cells & 6 Gy & microarray & {$[46]$} & - \\
\hline \multirow[t]{11}{*}{ Decreased } & $\begin{array}{l}\text { let-7c, let-7d, let-7e, miR-15a, } \\
\text { miR-30d, miR-92a, miR-125a, } \\
\text { miR-197, miR-221, miR-320b, } \\
\text { miR-342, miR-361, miR-374a, } \\
\text { miR-501, miR-671 }\end{array}$ & PC-3 cells & 10 Gy & NGS & [41] & \\
\hline & $\operatorname{miR}-17$ & & & & & Radiosensitization [52] \\
\hline & miR-17-92 cluster & PC-3, LNCaP and DU145 cells & $\begin{array}{l}5 \text { and } 10 \mathrm{~Gy}, \text { single } \\
\text { dose and } 0.5 \mathrm{~Gy} \times 10, \\
1 \mathrm{~Gy} \times 10 \text { fractionned } \\
\text { dose }\end{array}$ & microarray & {$[43]$} & - \\
\hline & $\operatorname{miR}-100$ & LNCaP cells & 6 Gy & microarray & {$[46]$} & Radiosensitization [53] \\
\hline & $\begin{array}{l}\text { miR-107, miR-122a, miR-133b, } \\
\text { miR-187, miR-196a, miR-487 }\end{array}$ & & & & & - \\
\hline & miR-145 & & & & & Radiosensitization [54] \\
\hline & miR-521 & & & & & Radiosensitization [55] \\
\hline & miR-106b & LNCaP cells & 6 Gy & microarray & {$[49]$} & Radioresistance [55] \\
\hline & miR-199a & & & & & - \\
\hline & $\begin{array}{l}\text { miR-133b, miR-135b, miR-143, } \\
\text { miR-196a, miR-218, miR-521 }\end{array}$ & C4-2 cells & 6 Gy & microarray & {$[46]$} & - \\
\hline & $\begin{array}{l}46 \text { miRNAs decreased notably } \\
\text { miR-141, miR-3607, miR-4284 }\end{array}$ & 22RV1-RR compared to $22 \mathrm{RV} 1$ cells & $\begin{array}{l}60 \text { Gy ( } 2 \text { Gy fractioned } \\
\text { doses) }\end{array}$ & microarray & {$[50]$} & - \\
\hline
\end{tabular}

Interestingly, PCa miRome could also be modulated by AR. Indeed, the AR by binding to androgen response elements (AREs) can directly regulate miRNA expression [63]. miR-21, known to induce radioresistance [64] and to play a role in CRPC [65], is a miRNA regulated by the AR [66].

Definitively concluding a miRNA is up- or downregulated by IR is difficult since findings are heavily influenced by the variations in methodology between research groups. As technology such as NGS becomes more accessible, larger datasets will hopefully help to decipher complex changes of miRNA expression following radiation and identify potential patterns which can be utilized clinically to evaluate radiation response.

miRNAs in DNA repair mechanisms induced by radiotherapy

IR induces DNA damage including double-strand breaks (DSBs), the most deleterious to cell survival. A major mechanism of radioresistance in cancer cells is altered expression of DDR components and DNA repair pathway such as NHEJ or homologous recombination (HR). Numerous studies have shown that miRNA expression changes in response to DNA damage in order to regulate DDR and DNA repair pathways [29, 33, 67]. 
To identify the impact of miRNAs on DNA repair and radioresistance, Hatano et al. transfected 810 different miRNA mimics separately into LNCaP-MLuc cells and then irradiated the miR-transfected cells with 4 Gy dose [55]. Eleven days after radiation treatment, MLuc activity was measured to determine cell viability. Among the miRNAs studied, 75 were categorized as radioprotective, in particular the miR-106b family, while 324 miRNAs were identified as radiosensitizing, notably miR-521. Further investigations on the candidate miRNAs highlighted in this screen need to be performed to verify and characterize their influence on DDR and DNA repair. For example, the role of miR-521 in radiosensitivity of PCa cells (C4-2 and LNCaP) was previously described by Josson et al., as it was down-regulated after radiation treatment, and further experiments identified a DNA repair protein, cockayne syndrome protein A (CSA), as a potential target of miR-521 [46]. Several other miRNAs have been shown to impair DNA repair through targeting repair response proteins. miR-890 and miR-744-3p directly target the DNA repair proteins mitotic arrest deficient 2 like 2 (MAD2L2) and RAD23 homolog B (RAD23B) respectively, in addition to indirectly reducing additional DDR proteins such as Ku80, xeroderma pigmentosum complementation group $\mathrm{C}$ (XPC), XRCC4-like factor (XLF) and cell leukemia 1 (MCL1) [55] (Fig. 2). In vivo, miR-890 mimic slows down the growth of $\mathrm{PCa}$ xenografts following IR treatment when compared with miRNA control and leads to a radiosensitive phenotype [55]. More recently, El Bezawy et al. showed that the overexpression of miR-205 in DU145 and PC-3 cell lines induced an increased sensitivity to radiation by impairing the ability of these cell lines to repair postIR DNA damage, and identified Protein Kinase C epsilon (PKCE) as a direct target of this miRNA [68]. $\mathrm{PKC \varepsilon}$ is known to trigger nuclear Epidermal Growth Factor Receptor (EGFR) accumulation, leading to the activation of DNA-dependent protein kinase (DNAPK) [69].

Regarding miRNAs altering homologous recombination, Mueller et al. showed that miR-99a and miR-100 are down-regulated in radioresistant $\mathrm{PCa}$ cells and up-

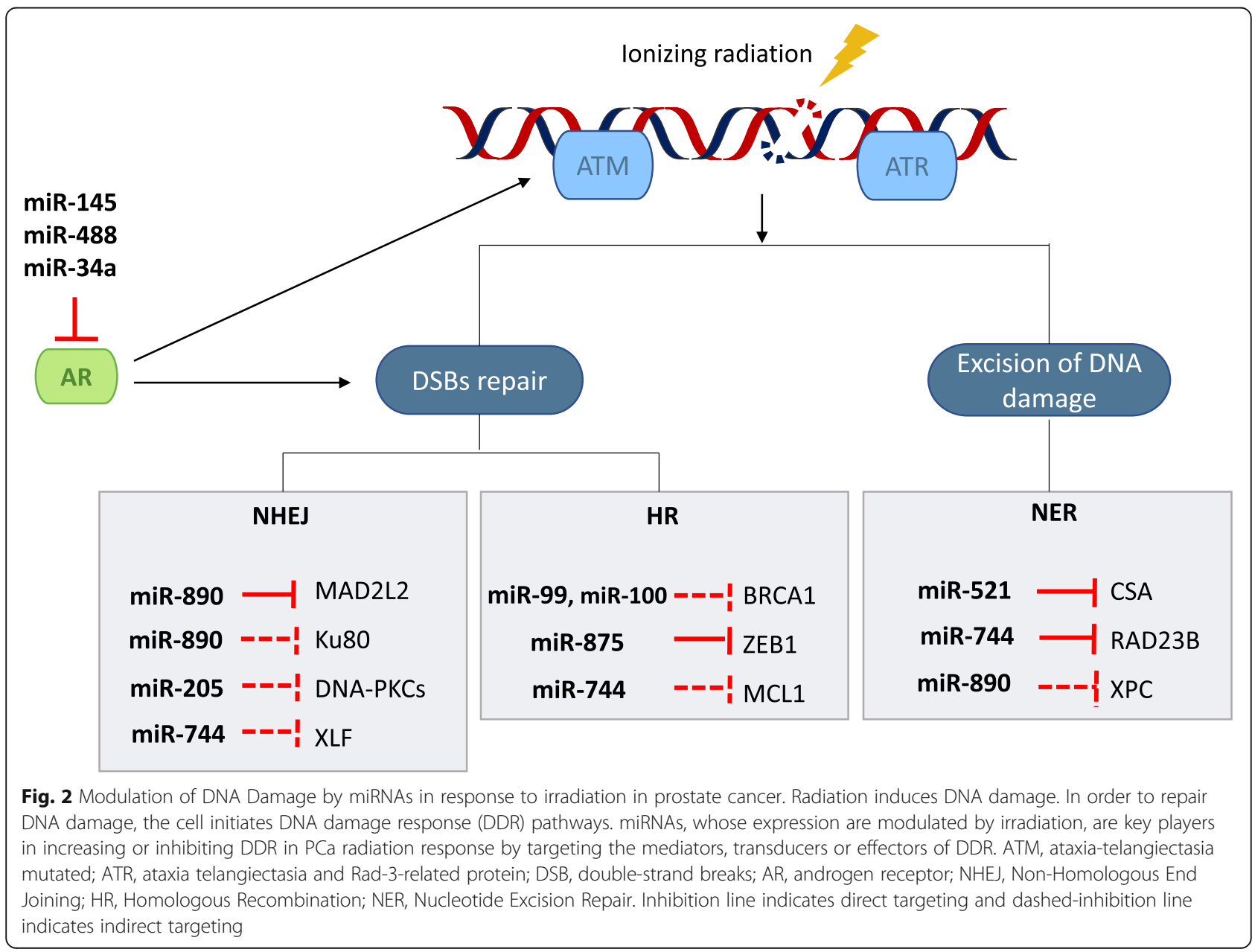


regulated following IR-induced DNA damage. The overexpression of these two miRNAs reduced the efficiency of DSB repair and increased in vitro radiosensitivity by targeting SNF2H (SWI/SNF-related matrix-associated actin-dependent regulator of chromatin subfamily A member 5, or SMARCA5), a chromatin-remodeling factor which recruits Breast cancer susceptibility gene 1 (BRCA1) to sites of DSBs [53]. Another tumor suppressor miRNA targeting DDR is miR-875-3p, which induces radiation sensitivity in $\mathrm{PCa}$ cells by inhibiting $\mathrm{HR}$ by regulating checkpoint kinase 1 (CHK1) expression and through down-regulation of Zinc Finger E-box-binding homeobox 1 (ZEB1), a protein implicated in epithelial to mesenchymal transition (EMT) [70] (Fig. 2).

It is also interesting to note, that the AR interacts with, affects, and is affected by DDR proteins, resulting in increased, but less faithful, repair of DNA damage and therefore formation of mutations [26, 71]. miR-145 directly targets $A R$ [72] and was shown to be downregulated after IR in LNCaP cells [46], while miR-488 and miR-34a have also been found to target the AR mRNA [43, 46, 73-75], suggesting they could play a role in radiation sensitivity through regulating AR-DDR feedback loops (Fig. 2).

\section{miRNAs in cell cycle progression after radiation}

Following IR-induced DNA damage, cell cycle progression is arrested at G1 and G2 checkpoints to allow time for the cell to repair this damage. Typically once DNA is repaired, the cell will re-enter the cell cycle, however, if it is unable to repair the damage it will undergo cell death (discussed in more detail in the following section) [76]. Cell cycle progression past checkpoints depends on cyclins, cyclin dependent kinases (CDKs), inhibitors, and also on transcription factors such as the E2F family, and each of these components can be regulated by miRNAs.

It has been suggested that one of the cyclins, cyclin D, is regulated after IR by several miRNAs, which are all overexpressed in response to IR. Cyclin D is involved in Retinoblastoma ( $\mathrm{Rb})$ protein phosphorylation to promote cell cycle progression [44]. Wang et al. demonstrated that miR-16-5p induces cell cycle arrest at G0/ G1 phase by targeting cyclin D1 in irradiated PCa cells [44], which was later confirmed by Takeshita et al. in mouse bone tissues [77] (Fig. 3). Cyclin D1 is also indirectly suppressed by cell cycle-related and expressionelevated protein in tumor (CREPT) which is targeted by miR-501 [41, 78]. The IR-induced down-regulation of miR-501 might further prevent cell cycle progression, and thereby radiosensitize $\mathrm{PCa}$ cells to radiotherapy. Two others miRNAs, let-7a and miR-154, are known to target cyclin D, isoform 2 [43, 46, 79-81]. As such, these miRNAs may act as radiosensitizers in $\mathrm{PCa}$ cells and might induce cell cycle arrest via cyclin D.
In $\mathrm{PCa}$, the $\mathrm{G} 2 / \mathrm{M}$ checkpoint can also be dysregulated directly by miRNAs following IR, for example miR-95 overexpression may enhance transit through the G2/M phase by targeting Sphingosine-1- phosphate phosphatase 1 (SGPP1 ) [40], which contributes to radioresistance. In contrast, miR-449a has been shown to induce cell cycle arrest at G2/M phase and enhance radiosensitivity in vitro and in vivo [47] (Fig. 3). Using an antagomir (anti-miR-449a), miR-499a expression was suppressed and increased cell proliferation was observed [48]. Conversely, after over-expressing miR-449a in PC-3 and DU145 cells using a plasmid construct, cell cycle arrest was observed [47]. Collectively, these results support the hypothesis that miR-499a is involved in cell cycle arrest, which impacts radiosensitivity. Further investigations identified Cell division cycle 25A (Cdc25A), a protein implicated in cyclin B activation and a mediator of $c-M y c$ function, as a direct target of miR-449a. $c-M y c$, which controls Cdc25A expression, is also observed as a target of miR-449a. Surprisingly, in the first publication by Mao et al., miR-449a is decreased in PCa DU145 and PC-3 cell lines after IR [47], but in a following publication, they reported that miR-499a is up-regulated in the LNCaP cell line following IR [48]. Thus, miRNA expression effects may be cell-line dependent, with downregulation of miR-449a in androgen-dependent prostate cells inducing radioresistance via alterations in cell cycle arrest.

CDK inhibitors can also be targeted by miRNAs, and this interaction is known to be modulated by radiation [82]. Several studies have demonstrated the role of miR106b on p21 regulation after IR [49,55] (Fig. 3). Li et al. have investigated the expression of miRNAs in LNCaP cells 24 hours after 6 Gy IR, and showed that the expression of several miRNAs was altered. This included miR106b, which appeared to be down-regulated up to 48 hours following IR. miR-106b is known to target p21, which results in suppression of cell cycle block and promotion of proliferation [49]. miR-106b could therefore be a therapeutic target for the population of radiationresistant PCa patients who fail to exhibit miR-106b decrease following radiotherapy. Another CDK inhibitor, p27, is targeted by miR-221/222 and miR-24 [83, 84] (Fig. 3). Following irradiation of PCa cells, miR-24 was found to be up-regulated [49], whereas miR-221 and miR-222 were decreased in radiosensitive PC-3 cells. These results were confirmed in $\mathrm{PCa}$ tissue using the TCGA dataset [41]. Conversely, miR-221 and miR-222 were found to be increased in radioresistant 22RV1-RR cells [50]. Thus, these miRNAs could play a role in promoting a radioresistant phenotype via negatively regulating CDK inhibitors, and their inhibition may impair the growth of $\mathrm{PCa}$ [51]. This axis could show promise for therapeutic interventions. 


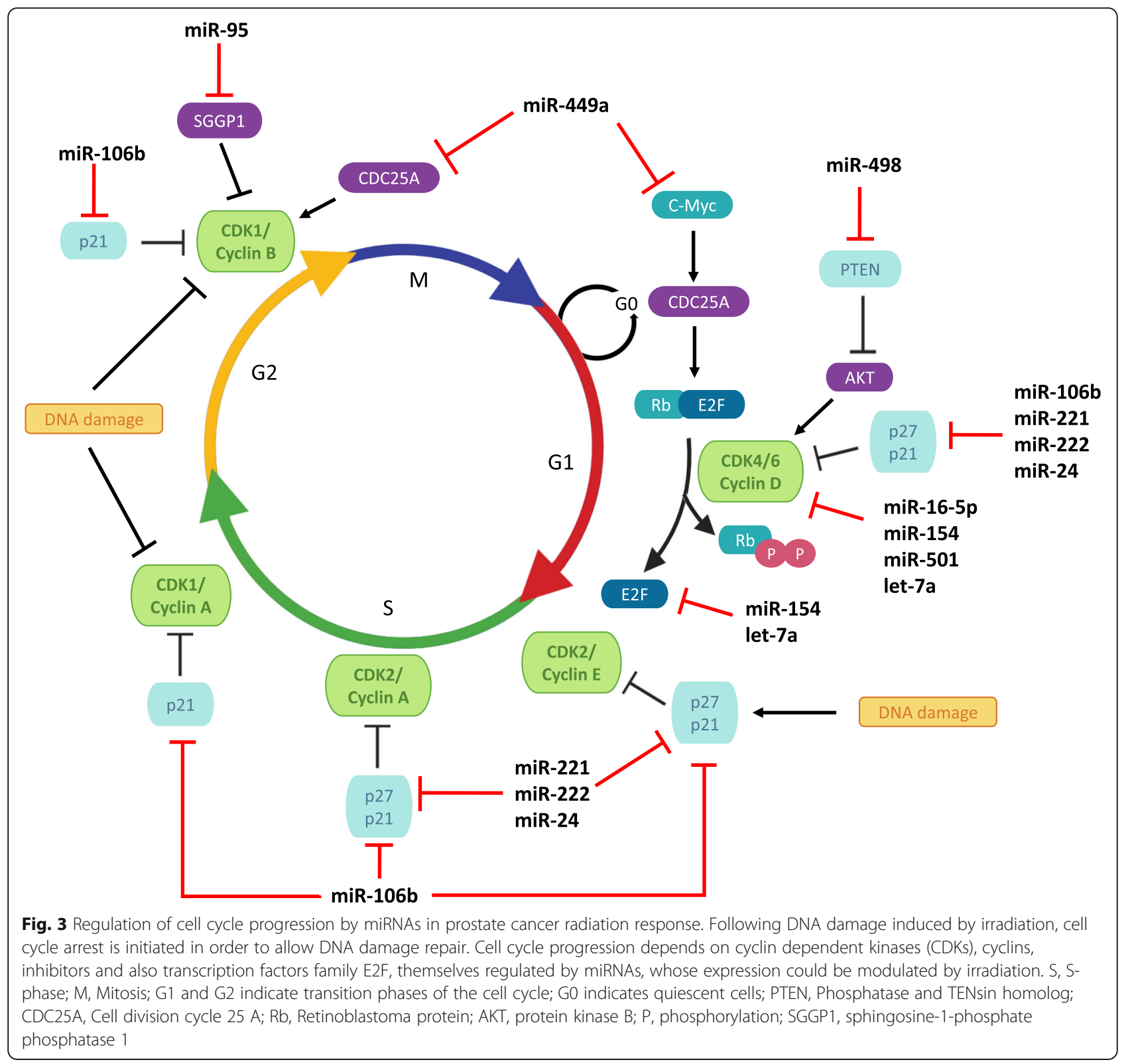

Finally, radiation response can also be regulated by miRNAs whose targets indirectly affect the cell cycle. In a recent publication, the phenotype of miR-498 was examined in DU145 and LNCaP cells after varying doses of ionizing radiation ( 1 to 8 Gy) [85]. miR-498 is implicated in proliferation progression of $\mathrm{PCa}$ cells and radioresistance by targeting Phosphatase and TENsin homolog (PTEN) (Fig. 3). PTEN is an important cell cycle regulator that suppresses the protein kinase $\mathrm{B}$ (AKT) signaling pathway, resulting in inhibition of cell cycle progression. Moreover, down-regulation of miR498 was shown to reduce PCa cell survival after IR. miR498 is dysregulated across various cancers, and it is also reportedly up-regulated in PCa cells [86]. Thus, it is suggested miR-498 over-expression could lead to PCa radioresistance through inhibition of PTEN.

miRNAs and cell death

IR-induced DNA damage causes cell death via multiple mechanisms including mitotic catastrophe, apoptosis, senescence and autophagy [87]. The mode of cell death following IR is determined by a wide variety of factors such as cell type, p53 status, radiation dose or fraction, and tumor oxygenation. In $\mathrm{PCa}$, mitotic catastrophe is considered the dominant mode of cell death and the major determinant of clonogenic cell survival following IR [88]. Mitotic catastrophe is a delayed form of cell death arising from unrepaired DNA damage as a result 
of dysregulated G2/M cell cycle checkpoint arrest and premature progression into mitosis. Aberrant chromosome separation from centrosome hyper-amplification results in formation of giant polyploid cells, which may go through several rounds of cell division before ultimately undergoing delayed apoptosis. Cell cycle arrest, DNA DSB repair, and cell death are tightly interconnected, and miRNAs may directly or indirectly influence one or all of the above to alter cancer radiosensitivity. As miRNAs affecting cell cycle arrest and DNA repair have been discussed in previous sections, this portion will focus on radiomodulating miRNAs with direct experimental analysis on cell death. One such example is miR-145, which sensitizes both LNCaP and PC-3 PCa cells to IR and predicts patient response to neoadjuvant radiotherapy [54]. Gong et al. subsequently determined that decreased clonogenic survival with high miR-145 was not due to changes in apoptosis but rather increased number of cells undergoing mitotic catastrophe as a result of significantly reduced DSB repair. In this sense, Ye et al. showed that miR-145 targeted the DNA damage repair associated Helicase-lie transcription factor (HLTF) [89], implicated in radioresistance in cervical cancer [90]. Another target of miR-145, also implicated in radiosensitivity, was SENP1 [91]. SENP1 belongs to the small ubiquitin-like modifier (SUMO)-specific protease family, which deconjugates modified proteins to maintain the level of SUMOylated and un-SUMOylated substrates. In PCa, SENP1 modulates several oncogenic pathways, including AR, c-Jun and Cyclin D1 [92]. Thus, as described in PC-3 cell lines, miR-145 induced cell cycle arrest through the downregulation of SENP1 [91].

miR-32 is a $\mathrm{PCa}$ oncomiR which when overexpressed increases radioresistance of PC-3 and DU145 cells, as evaluated using MTT assay, and reduces the percentage of apoptotic cells while inducing autophagy following 2Gy IR [93]. The authors demonstrated miR-32 directly targets DAB2 interacting protein (DAB2IP), the loss of which has previously been shown to promote radioresistance in PCa through enhanced DSB repair, G2/M checkpoint control, and evasion of apoptosis [93, 94]. An opposite effect is observed with radiosensitizer miR99a in C4-2 cells, with repression of chromatin remodeling protein SNF2H by miR-99a decreasing DSB repair following IR [53]. In addition, overexpression of miR-99a increases PARP (poly ADP ribose polymerase) cleavage, a recognized marker of late apoptosis which is cleaved by caspase-3. The authors suggest that miR-99a decreases DSB repair following IR resulting in increased cell death via apoptosis. Additional miRNAs affecting IR-induced apoptosis are miR-498 and miR-449a, which target PTEN and $\mathrm{Rb}$ respectively. miR-449a stimulates radiosensitivity through increased $G 2 / \mathrm{M}$ arrest and higher apoptosis induction, while miR-498 promotes radioresistance through reducing radiation-induced apoptosis indicated by lower caspase $3 / 7$ activity $[47,85]$.

\section{miRNAs under hypoxia}

Hypoxia is a biological phenomenon associated with tumor progression and acquisition of an aggressive phenotype in solid tumors [95] and radioresistance [96]. The combination of tumor growth and an inadequate tumor vasculature leads to poor perfusion of nutrients and oxygen to the TME and cancer cells [97]. Because of this, tumor cells are exposed to transient hypoxic conditions, which establishes an environment that favors tumor progression and metastasis. Hypoxia is also impacted by IR and modifies radiation response, notably through the alterations in miRNA expression [98]. $\mathrm{Nu}$ merous studies have suggested that hypoxia triggers EMT in several types of solid tumors, particularly PCa. Hypoxia is known to increase zinc finger protein SNAI1 (SNAIL) and twist family bHLH transcription factor 1 (TWIST1) activity leading to the inhibition of Ecadherin [99]. Wang et al. have investigated the relationship of miR-301a and miR-301b to hypoxia and radioresistance. They found that these two miRNAs are hypoxia-responsive and enhance PCa radioresistance by targeting N-myc downstream-regulated gene 2 (NDRG2) [100], a protein which suppresses EMT via the inhibition of signal transducer and activator of transcription 3 (STAT3)/SNAIL signaling [101] (Fig. 4). Hypoxia also induces a decrease of miR-124 and miR-144 [102], which reduces their inhibition of pim-1 oncogene (PIM1) and leads to EMT [103], thereby enhancing radioresistance in an in vitro model of PCa [102] (Fig. 4).

Several hypoxia-induced miRNAs have been investigated as they have been thought to regulate radiosensitivity through changes in autophagy and apoptosis. Overexpression of hypoxia-induced miR-301a or miR301b increased clonogenic survival and lowered radiation-induced apoptosis in LNCaP cells [100]. NDRG2 is a cell-stress response gene targeted by both miR-301a or miR-301b, which regulates numerous survival related molecular pathways including STAT3, SAPK/JNK, Bax, and PI3K/Akt signaling [104]. Conversely, miR-124, miR-144, miR-30a, and miR-205 are all down-regulated in hypoxia, and when overexpressed in PCa cells significantly increased caspase- 3 apoptotic activation and inhibited autophagy post IR, while reducing clonogenic survival $[42,102]$.

\section{miRNAs in tumor microenvironment}

The TME is comprised of a variety of cell types including tumor cells, endothelial cells, immune cells, as well as extra-cellular features such as the extracellular matrix that surrounding cancer cells. All these components that make up the TME components are known to be affected 


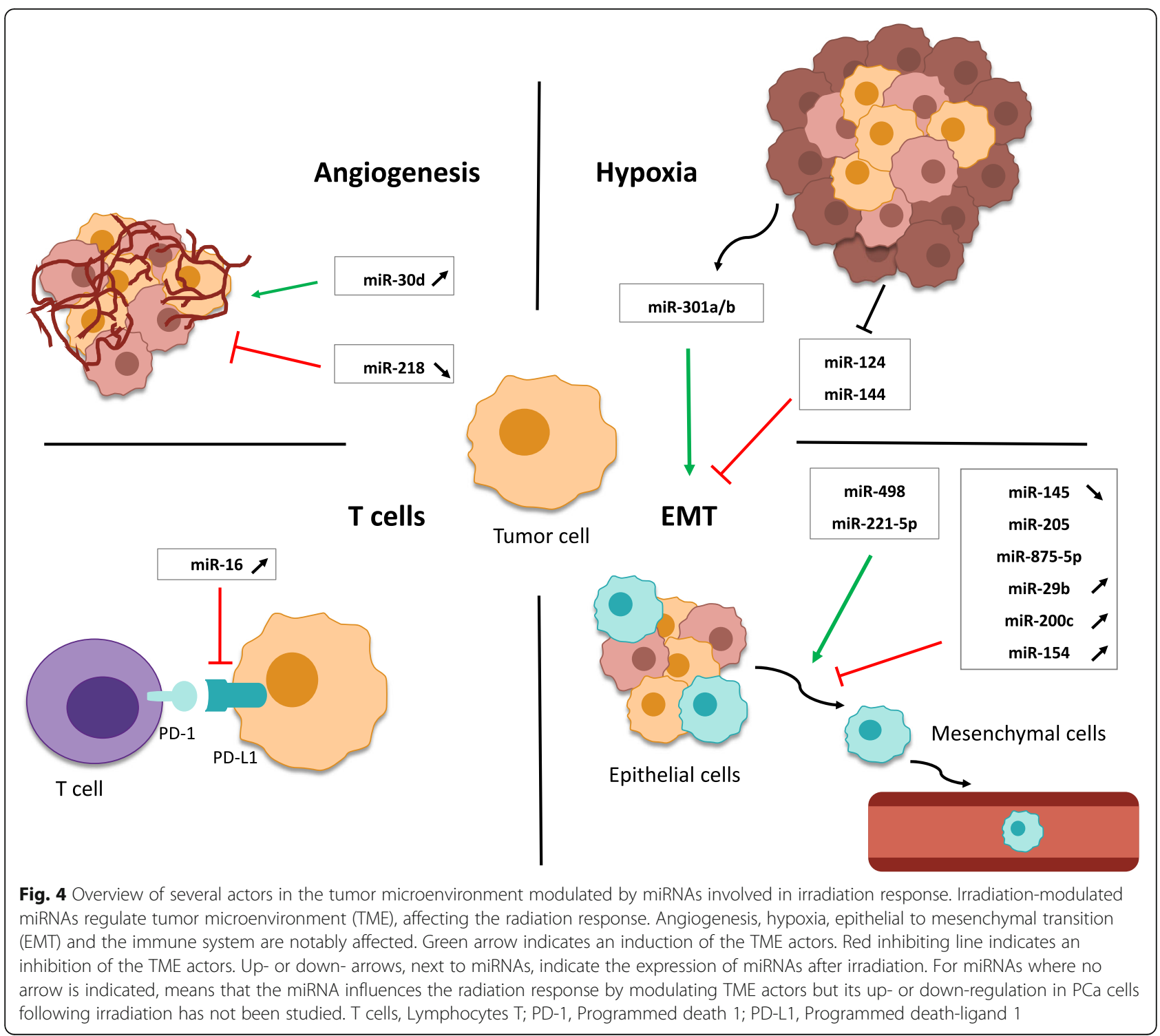

by IR and may therefore modulate therapeutic response $[19,105]$. In response to IR, the TME can promote immunogenic cell death through tumor antigen release [106] and induce vascular remodeling to improve radiotherapy efficiency [14], while conversely IR can also induce radioresistance through the promotion of EMT [107]. miRNAs are known to be involved in regulating the TME and radiotherapy response [108, 109].

Tumor growth depends on angiogenesis, a normal physiological process that involves the formation of new blood vessels through proliferation, migration, and differentiation of endothelial cells. Angiogenesis requires coordination of various signaling pathways and cellular activation factors, notably vascular endothelial growth factor (VEGF) [110]. It has been estimated that cancer cells can only reach a maximum volume of $1-2 \mathrm{~mm}^{3}$ in the absence of a vascular system [110]. In order for tumors to proliferate and metastasize, angiogenesis must first take place, and miRNAs have been described to regulate this process [111-113]. Lin et al. observed that miR-30d promotes angiogenic proliferation and migration, and enhances the ability of $\mathrm{PCa}$ cells to recruit endothelial cells via myosin phosphatase targeting subunit 1 (MYPT1)/c-JUN/VEGF-A pathway (Fig. 4). The over-expression of miR-30d is thus associated with advanced cancer progression and an unfavorable prognosis [114]. After IR, miR-30d became decreased in PC-3 cells [41] and it was therefore suggested that miR-30d may increase the efficacy of radiotherapy. In the case of miR218 , its down-regulation contributes to angiogenesis by activating Rapamycin-insensitive companion of mammalian target of rapamycin (RICTOR)/VEGFA pathways [115]. This miRNA has also been shown to be downregulated after irradiation of a C4-2 cell line [46] (Fig. 4). 
Immune cells are critical players within the TME [116]. Immune responses affect cancer development by suppressing or destroying cancerous cells, but these cells eventually develop mechanisms to escape immune surveillance. miRNAs play an important role in the TME by targeting immune cells. For example, miR-16 enhances radiotherapy efficiency in $\mathrm{PCa}$ through cytotoxic $\mathrm{T}$ cell activation in the TME by suppressing the immune checkpoint regulator PD-L1 programmed death protein 1 (PD-L1) in PCa cells [45] (Fig. 3). miR-16 overexpression in PCa cells after IR may promote radiosensitivity [44]. PD-L1, a ligand expressed on tumor cells, interacts with programmed-death 1 (PD-1) on T cells in order to inhibit CD8+ cytotoxic T lymphocyte survival and proliferation [117]. Thus, PD-L1 down-regulation by miR-16 could enhance immune anti-tumor activity.

\section{miRNA during the epithelial-mesenchymal transition (EMT)}

EMT is characterized by the loss of the polar and adhesive epithelial features, enhanced cell motility and the acquisition of mesenchymal characteristics. It is a complex mechanism which involves modification of various signaling pathways. These pathways are regulated by several transcriptional factors, notably SNAIL, Zinc finger protein SNAI2(SLUG), TWIST 1/2 , ZEB 1/2 [118]. In PCa, miRNAs have been shown to induce EMT by regulating these transcription factors directly [119, 120]. Some miRNAs implicated in EMT inhibition have been found to be down-regulated by IR. Indeed, miR-145 has been described to target ZEB2 [121] and human enhancer of filamentation 1 (HEF1) [122] (Fig. 4), and was shown to have reduced expression after irradiation [46], consequently promoting EMT, bone invasion, and decreasing the effectiveness of radiotherapy. miR-205, essential for the maintenance of the basal membrane epithelium in the prostate gland, is implicated in the modulation of IR response [123, 124]. It has been found to be down-regulated in PCa cells compared to normal prostate tissue [124]. In further studies, the overexpression of miR-145 enhanced radiosensitivity in vitro and in vivo [68], through targeting ZEB1 which increased E-cadherin expression [125] (Fig. 4). Another miRNA which can radiosensitize is miR-875-5p, which is down-regulated in $\mathrm{PCa}$ and enhances tumor control after radiation by preventing EMT, as it indirectly targets ZEB1 [70, 126]. Other miRNAs involved in the inhibition of EMT after IR have been shown to be upregulated, such as miR-29b and miR-200c [49] (Fig. 4). miR-29b was found to inhibit EMT and subsequently reduce PCa metastasis in vivo, by inhibiting the expression of SNAIL [127]. miR-200c, a known tumor suppressor miRNA, also suppresses invasion by directly targeting ZEB1 and ZEB2 [128-130]. Thus, miR-29 and miR-200c might enhance the efficacy of radiotherapy via these mechanisms. Radiation also alters the expression of miR-154 in C4-2 cells [46], and over-expression of this miRNA is known to inhibit EMT by targeting highmobility group A2 (HMGA2) [131] (Fig. 4).

Radiation response can also be influenced by the expression of miRNAs implicated in the induction of EMT. miR-498 induces a radioresistant phenotype in PCa cells by directly targeting PTEN [85]. A major tumor suppressor, PTEN inhibition promotes cancer metastasis and it is frequently loss during PCa progression, with up to $70 \%$ in late stage [132]. With downregulation or inhibition of PTEN, AKT can be activated, which increases expression of Vimentin, inhibits expression of E-cadherin by SNAIL [133], and ultimately leads to invasion and migration (Fig. 4). In PCa, proliferation and migration are also enhanced by miR-221-5p which inhibits the tumor suppressor gene suppressor of cytokine signaling protein 1 (SOCS1) [134] (Fig. 4). This miRNA was found to be down-regulated in PC-3 cells [41] and up-regulated in 22RV1-RR cells [50] after irradiation. Thus, miR-221-5p might be involved in promoting the radioresistant phenotype observed in these cells. However future mechanistic studies must be performed to definitively determine its role.

\section{miRNA and Cancer stem cell (CSC)}

Accumulating evidences supports that CSC are an important subset of cancer cells that play important roles in radiation response, radioresistance and relapse in $\mathrm{PCa}$ [135], but a limited number of experiments described the implication of miRNAs in these processes. CSC populations may be enumerated using cell surface markers such as the adhesion molecule CD44. CD44 expression is associated with radioresistance in PCa cells [136]. Liu et al. have identified $\mathrm{CD} 44$ and $\mathrm{EZH} 2$ as direct target of miR-141 [60]. This miRNA is downregulated in Prostate CSC (PCSC) populations but highly expressed in prostate cancer tissues. In PC-3 and LNCaP cells, expressions of Nanog, Oct4 and EZH2 were correlated with miR-21 under hypoxia [95]. Another study showed that miRNA expression profile in PCSC was dependent on the differentiation stage [137].

\section{miRNAs in extracellular vesicles}

Extracellular vesicles (EVs) are a heterogeneous population of membrane vesicles of various origins, secreted by cells into the extracellular space $[138,139]$. The main subtypes of EVs are microvesicles and exosomes, which are distinguished based upon their biogenesis, release pathways, size, content, and function. Exosomes are small vesicles $(50-150 \mathrm{~nm}$ in diameter) secreted by almost all cell types, tumoral or not. They are formed via inward budding of endosomal membrane during 
maturation of multi-vesicular endosomes (MVEs) and later secreted when the MVEs fuse with the plasma membrane [138]. These small vesicles play a role in intercellular communication by transferring their contents in order to influence many physiological and pathological functions in the recipient cell [140, 141]. It has been suggested that EVs may be involved in cancer progression and recurrence in this way [142]. In human body fluids, such as blood and urine, miRNAs are protected from endogenous RNAse activities by their interaction with proteins or lipids, or their encapsulation into exosomes [140, 143, 144]. PCa-derived exosomes have been found to be released in diverse biofluids and could serve as a liquid biopsy for PCa [145], which will be discussed in more detail in the following section. Cellular stress, which can be caused by IR, can affect the molecular composition of miRNAs in exosomes, and also increase loco-regional exosome secretion.

In a recent study, exosomal miRNAs in the sera from $11 \mathrm{PCa}$ patients (6 intermediate-risk and 5 high-risk disease) treated with radiotherapy were analyzed [146] (Table 2). A comparative analysis was performed looking at the expression of miRNAs before and after radiotherapy. Using Nanosight, they showed that exosome concentrations in serum were higher in $\mathrm{PCa}$ patients compared to healthy individuals, and this trend held true following IR. After radiotherapy, miR-21-5p and let-7a$5 p$ were found to be significantly higher in serumderived exosomes of high-risk (i.e. Gleason 7 or higher $(3+4,4+4,4+5$ or 8$)$ and pathological $\mathrm{T}$ stage (cT1c, cT3a, pT3 or pT3a)) PCa patients compared to intermediate-risk (i.e. Gleason 7 or under $(3+3,3+4$ or $4+3$ ) and pathological T stage (cT2a, cT2b or cT1c))
PCa patients. However, due to the small sample size, these results require validation within larger patient cohorts.

$\mathrm{Yu}$ and colleagues have also evaluated exosomal miRNAs to monitor the efficacy of carbon ion radiotherapy (CIRT) [150] (Table 2), which has superior dose distribution, higher linear energy transfer and increased biological effectiveness compared to conventional photonbased external beam radiation. To do so, the authors analyzed exosomal miRNAs from the sera of 8 patients with localized prostate cancer exposed to CIRT. They observed deregulated expression of 57 miRNAs after CIRT, and 25 which correlated with PSA (prostate specific antigen). They next showed that patients responding to CIRT, based on PSA $<0.2 \mathrm{ng} / \mathrm{mL}$ after CIRT, had higher expression of 9 miRNAs (miR-200c-3p, miR323a-3p, miR-379-5p, miR-409-3p, miR-411-5p, miR493-5p, miR-494-3p, miR-543 and miR-654-3p) in their sera compared to non-responders (PSA $>0.2 \mathrm{ng} / \mathrm{mL}$ after CIRT). They also performed a comparison of miRNA content in exosomes before and after CIRT, which correlated miR-379-5p and miR-654-3p expression with an effective response to CIRT. This study is the first to explore the modulation of exosomal miRNAs expression in PCa after CIRT exposure. However, these results should be interpreted with caution due to the small cohort of patients and may be specific to CIRT treatment.

It has been shown that IR treated cells secrete exosomes that can be taken up by non-irradiated neighboring cells and induce biological changes via the bystander effect $[157,158]$. These IR-induced exosomes may promote radioresistance, leading to tumor progression and

Table $\mathbf{2}$ exosomal miRNAs in radiotherapy response in prostate cancer

\begin{tabular}{|c|c|c|c|c|c|c|}
\hline miRNA & Biomarkers & Biofluids & Main results & Cohorts & References & Targets \\
\hline let-7a-5p & Efficacy of RT & \multirow[t]{2}{*}{ Serum exosomes } & \multirow{2}{*}{$\begin{array}{l}\text { Upregulated in exosomes } \\
\text { of high-risk PCa patients } \\
\text { after RT compared to } \\
\text { intermediate-risk PCa patients }\end{array}$} & \multirow{2}{*}{$\begin{array}{l}11 \text { PCa patients } \\
\text { (6 intermediate-risks, } \\
5 \text { high-risk disease) }\end{array}$} & \multirow[t]{2}{*}{ [146] } & - \\
\hline miR-21 & $\begin{array}{l}\text { Diagnostic/ efficacy } \\
\text { of RT }\end{array}$ & & & & & $\begin{array}{l}\text { PTEN [147], MARCKS } \\
\text { [148], ANP32A, } \\
\text { SMARCA4 [149] }\end{array}$ \\
\hline miR-200c-3p & \multirow[t]{9}{*}{ Efficacy of CIRT } & \multirow[t]{9}{*}{ Serum exosomes } & \multirow{9}{*}{$\begin{array}{l}\text { Upregulation in exosomes } \\
\text { is associated with a good } \\
\text { response to CIRT }\end{array}$} & \multirow{9}{*}{$\begin{array}{l}8 \text { PCa patients } \\
\text { ( } 3 \text { intermediate risk, } \\
2 \text { high risk, } 3 \text { very } \\
\text { high risk) }\end{array}$} & \multirow[t]{9}{*}{ [150] } & ZEB1, ZEB2 [128] \\
\hline $\operatorname{miR}-323-3 p$ & & & & & & p73 [151], AdipoR1 [152] \\
\hline miR-379-5p & & & & & & - \\
\hline miR-409-3p & & & & & & PHC3, RSU1,TUSC1 [153] \\
\hline miR-411-5p & & & & & & - \\
\hline miR-493-5p & & & & & & c-Met, CREB1, EGFR [154] \\
\hline miR-494-3p & & & & & & CXCR4 [155] \\
\hline miR-543 & & & & & & RKIP [156] \\
\hline miR-654-3p & & & & & & AR [74] \\
\hline
\end{tabular}

$R T$ radiotherapy, CIRT carbon ion radiotherapy, PCa prostate cancer, PTEN phosphatase and TENsin homolog, MARCKS myristoylated alanine-rich protein kinase $\mathrm{C}$ substrate, ANP32A acid nuclear phosphoprotein 32 family member A, SMARCA4 SWI/SNF related matrix associated actin dependent regulator of chromatin subfamily A member 4, AdipoR1 Adiponectin receptor 1, PHC3 polyhomeotic homolog 3, RSU1 Ras suppressor protein 1, TUSC1 tumor suppressor candidate 1, CREB1 CAMP responsive element binding protein 1, EGFR epidermal growth factor, CXCR4 CXC chemokine receptor 4, RKIP Raf kinase inhibitor protein, AR androgen receptor 
the formation of a pre-metastatic niche. Previous examples have indeed shown a resistance transfer by exosomes in breast cancer carcinoma [159, 160], head and neck cancer [161] and glioblastoma [162]. The presence of miRNAs in the circulation may make them a promising source of biomarkers for improving PCa management and monitoring treatment response following radiotherapy.

\section{miRNAs as biomarkers}

Improved clinical outcomes for patients with $\mathrm{PCa}$ are highly dependent on the tests we use to detect and monitor disease. Indeed, physicians and scientists are limited by the current technologies available at hand to understand this disease and its trajectory. In PCa, the discovery of PSA and integration of magnetic resonance imaging, have made huge strides in assisting with the diagnosis of PCa. Despite this, histopathological analysis of a biopsy specimen remains the gold standard test for $\mathrm{PCa}$ diagnosis and it is required for prognostication and treatment planning [163]. However, the core needle biopsy is not without significant side effects. From pain and bleeding, to infection with risk of progression to sepsis [164], these complications are not to be taken lightly. As such, prophylactic antibiotics are routinely administered to prevent such risks, but in 2019 with a rise of antibiotic-resistant bacterial strains, this practice must also not be overlooked. There is a significant clinical need to move toward developing non-invasive tests for cancer diagnosis, prognosis and prediction.

The field of circulating biomarkers (i.e. from whole blood, serum, plasma, and urine) has exploded in recent years. These "liquid biopsies" are collected from simple, non-invasive blood draws and urine samples, which harbor minimal (if any) side effects for patients. Once finetuned, the possibilities are really endless for which clinical setting circulating biomarkers could be used in - diagnostic, predictive, prognostic - and they would open doors to new ways of monitoring the progression of disease and response to therapies.

In PCa, there are a few commercially-available circulating biomarker tests. ExoDx Prostate (IntelliScore) [165] and PCA3 [166, 167] utilize urine samples, collected after a digital rectal exam (DRE). They use a gene-based or non-coding RNA signature, respectively, to help clinicians identify patients who are more likely to harbor clinically-significant PCa (i.e., Gleason score 7 or higher), and thus would benefit from a prostate biopsy. The 4Kscore Test $[168,169]$ is blood-based test that uses a panel of four kallikreins to predict the likelihood of a clinically-significant cancer. Although there are no commercially-available miRNA signatures, there are many that have been described in the literature, as previously reviewed [170, 171]. A few studies of note will be described in detail here. Alhasan et al. found a 5-miR (miR-200c, miR-605, miR-135a*, miR-433, and miR106a) serum signature to identify patients with very high-risk PCa (i.e. Gleason $8(4+4$ or $5+3)$ and Gleason 9) [172]. Hoey et al. identified a 4-miR (miR-20a, miR20b, miR-106a, and miR-106b) signature that stratifies PCa patients into low- and high-risk categories after radical prostatectomy [173]. Post-radical prostatectomy is a particularly important clinical setting for circulating biomarkers to detect biochemical recurrence and identify patients who would benefit from adjuvant therapy. A serum-based 3-miR (miR-223, miR-24, and miR-375) score was developed by Liu et al. to identify males on active surveillance who have indolent $\mathrm{PCa}$ compared to those with aggressive disease who need to be treated [174]. miR-1246 has been described as an serum exosomal biomarker to distinguish benign and aggressive $\mathrm{PCa}$ [175]. miR-1290 and miR-375 in the plasma were associated with significantly poorer overall survival in patients with castrate-resistant metastatic PCa [176]. Jeon et al. found a urine-based 7-miR (miR-3195, let-7b-5p, miR144-3p, miR-451a, miR-148a3p, miR-512-5p, and miR431-5p) signature that identifies high-risk $\mathrm{PCa}$ patients with high accuracy (AUC of 0.74, 95\% CI $=0.55-0.92$ ) [177], and this miRNA signature was stable over time. It is of particular relevance to note the unique superiority of a urine-based biomarker for PCa, as Pellegrini et al. discovered that urine collected after a DRE is enriched in prostate-specific markers [178]. They found that postDRE urine EVs contain prostate-derived RNAs, which were able to distinguish patients with low-risk (Gleason 6) and intermediate- and high-risk (Gleason 7 and above) PCa.

In regards to biomarkers of radiotherapy response, Zedan et al. identified miR-221 to be decreased in patient plasma after RT [179]. As previously mentioned, miR-221 expression is decreased in radiosensitive PC-3 cells [49] and increased in radioresistant 22RV1-RR cells [50]. Thus, the modulation of this miRNA might be investigated as a biomarker to monitor radiotherapy response. Further studies need to be performed to confirm that miR-221 could be used since biomarkers from biofluids do not necessarily reflect the miRNA profile of the tumor cells.

The temporal stability of miRNA in biofluids is a significant feature of an ideal biomarker. Since miRNA biomarker signatures can remain stable over time, an important application is their potential to non-invasively monitor disease progression or treatment response (i.e. before and after surgery, radiotherapy, hormone therapy and chemotherapy, as well as throughout the course of treatment). Various circulating miRNAs have been described for their predictive biomarker utility to distinguish patients who would benefit from treatment, thus 
personalizing management decisions [180-184]. Circulating miRNAs have even been used in the setting of identifying which patients have a higher risk of treatment toxicity. A study by Higgins et al. found that lower expression of miR-6821 and miR-1290 in the serum of patients with squamous cell carcinoma of the head and neck was associated with increased probability of developing acute and late radiationinduced toxicity [185]. A study by Lin et al. looking at circulating miRNAs in CRPC patients treated with docetaxel, found that miRNAs isolated from patient blood were associated with PSA response and overall survival using pre-docetaxel levels, or the direction of post-docetaxel change from baseline levels [181]. However, to the best of our knowledge, there are no circulating miRNA biomarkers described for the purpose of predicting response to or benefit of receiving radiotherapy in prostate cancer.

There are various characteristics of miRNAs that make them particularly attractive candidates for biomarker development, as previously reviewed by Schwarzenbach et al. [171]. miRNAs are highly stable in the blood and urine due to their association with proteins (such as AGO) or their encapsulation in EVs $[171,186]$. After blood draw, miRNAs can remain stable after incubation at room temperature and after undergoing repeat freeze-thaw cycles [186]. They can easily be detected with a standard qRT-PCR, which offers high sensitivity and specificity for a relatively low cost compared to other biomarker assays [171]. NGS has the ability to identify novel miRNA, and distinguish miRNA with similar sequences and those of splice variants (isomiRs) [171]. NGS deep sequencing can also assess genome-wide expression, however, this improved technology comes with a high financial cost [171]. Last but not least, miRNAs can be readily found in all body fluids, not just blood and urine [187].

Before non-invasive miRNA biomarkers can safely and effectively be translated into clinical studies and practice, various logistical issues must be addressed. For one, a standardized test for assessing the expression levels of blood and/or urine miRNA must be established. There is known to be large variability between platforms [188], even though individual platforms show very high correlations between technical replicates [189]. Aside from downstream technologies, laboratory reagents and protocols must also be standardized. It has been found that the specific anticoagulants (i.e. EDTA, heparin, citrate) used in blood collection tubes can affect downstream qRT-PCR analysis [190]. Indeed, determining which miRNA signature from the literature is superior to be used for the desired clinical setting, and reproducibility of this particular miRNA signature must be determined using large, prospective, multi-institutional cohorts.

Although there is still much work to be done before non-invasive miRNA biomarkers can begin to be used in the clinical setting, miRNAs show significant promise as a future non-invasive biomarker for cancer diagnosis, treatment prediction, and prognostication.

\section{Future perspectives}

There are currently very limited publications on the role of miRNAs in regulating PCa radiotherapy response and mediating PCa radioresistance $[40,41,43,44,46,49$, 50]. Moreover, the majority of these studies are performed on cell lines in vitro, and miRNAs found altered by IR in one study are not necessarily observed in others. This could be due to differences in IR doses and delivery methods, or variations between cell lines. Future studies are needed to explore miRNAs dysregulated by IR using not only PCa cells lines but also validation with patient samples.

In addition, the functional role of these miRNAs in cellular response to IR is not well understood and is largely in the infancy of discovery. Although miRNA can target a multitude of mRNAs, their function may be due to their regulation of only a select few. Thus, potential targets of miRNAs involved in radioresistance need to be thoroughly investigated in order to delineate true contributors to resistance so that novel therapeutic interventions will be focused on downstream components to overcome radioresistance. To our knowledge, there are no reports on miRNAs involved in ROS signaling, and only a few on hypoxia signaling and angiogenesis, in PCa following radiotherapy. Furthermore, no investigations have focused on the effect of exosomal miRNAs from PCa modulated by IR, and their impact on the tumor microenvironment. Thus, it will be beneficial for investigations to fill-in these missing gaps in radiobiology, for example the role of IR-induced exosomal miRNAs on immune escape. Indeed, Vignard et al. recently report that several miRNAs from melanomaderived exosomes participate to tumor immune escape by reducing CD8+ $\mathrm{T}$ cell response [191]. This might also be the case in prostate cancer following alteration of exosomal miRNA expression, which could lead to an enhancement in radioresistance.

Finally, it is essential to identify biomarkers to support the use of PSA in diagnosis and disease monitoring to improve accuracy. The detection of changes in circulating miRNAs shows promise as a prognostic indicator to differentiate between indolent and aggressive disease, and to predict radiation response in $\mathrm{PCa}$ to individualize treatment for patients. 


\section{Conclusion}

Radiation therapy is a critical modality of treatment for prostate cancer patients. Despite its delivery with curative intent, radioresistance frequently occurs and the underlying mechanisms are poorly understood. It is well characterized however, that ionizing radiation induces aberrant expression of miRNAs. These miRNAs, which are important regulators of gene abundance, play a role in radioresistance by modulating key cellular pathways that mediate radiation response. Overcoming radioresistance is a significant clinical challenge in prostate cancer management. Thus, identifying non-invasive biomarkers to inform treatment decisions in the clinic are desperately needed, and it is likely that miRNAs could be useful for this purpose. Furthermore, highlighting the targets of deregulated miRNAs will open doors for future therapies to sensitize prostate tumors to radiotherapy and improve tumor control. Various technologies may prove useful in this setting: miRNA mimics to overexpress tumor suppressor miRNAs decreased by radiotherapy, or small interfering RNAs and antisense oligonucleotides to inhibit oncomiRs up-regulated after radiotherapy. However, the delivery of these future treatments is still challenging due to the plethora of downstream targets that each miRNA can regulate. Therefore, it is imperative we untangle the cellular complexities in $\mathrm{PCa}$ radiotherapy resistance in order to improve $\mathrm{PCa}$ treatment and tumor control. Understanding the role of miRNAs in this setting brings us one step closer to achieving this goal and ultimately improving patient outcomes.

\footnotetext{
Abbreviations

3'UTR: 3' untranslated region; Ack1: Activated CDC42 kinase 1;

ADT: Androgen Deprivation Therapy; AGO: Argonaute; AKT: Protein kinase B; AR: Androgen receptor; AREs: Androgen Response Elements; ATM: Ataxia-

Telangiectasia Mutated; BRCA1: Breast cancer susceptibility gene 1; Cdc25A: Cell division cycle 25A; CDKs: Cyclin dependent kinases:

CHK1: Checkpoint kinase 1; CIRT: Carbon ion radiotherapy; CREPT: Cell cyclerelated and expression-elevated protein in tumor; CRPC: Castration-Resistant Prostate Cancer; CSA: Cockayne syndrome protein A; CSC: Cancer Stem Cell; DAB2IP: DAB2 interacting protein; DCs: Dendritic cells; DDR: DNA damage response; DNA-PK: DNA-dependent protein kinase; DRE: Digital Rectal Exam; DSBs: Double-strand breaks; EGFR: Epidermal growth factor receptor; EMT: Epithelial to mesenchymal transition; EVs: Extracellular vesicles: EZH2: Enhancer of zeste 2 polycomb repressive complex 2 subunit; HEF1: Human enhancer of filamentin 1; HIF-1a: Hypoxia-inducible factor 1a; HLTF: Helicase-lie transcription factor; HMGA2: High-motility group A2; HR: Homologous recombination; IR: lonizing radiation; MAD2L2: Mitotic arrest deficient 2 like 2; MCL1: Myeloid cell leukemia 1; miRNAs: microRNAs; MVEs: Multi-vesicular endosomes; MYPT1: Myosin phosphatase targeting subunit 1; ncRNAs: Non-coding RNAs; NDRG2: N-myc downstream-regulated gene 2; NGS: Next generation sequencing; NHEJ: Non-homologous end joining; PARP: Poly ADP ribose polymerase; PCa: Prostate cancer; PCSC: Prostate Cancer Stem Cell; PD-1: Programmed-death 1; PDL1: Programmed-death ligand 1; PIM1: Pim-1 oncogene; PKC $\varepsilon$ : Protein kinase C epsilon; PSA: Prostate specific antigen; PTEN: Phosphatase and TENsin homolog; RAD23B: RAD23 homolog B; Rb: Retinoblastoma protein; RICTOR: Rapamycin-insensitive companion of mammalian target of rapamycin; RISC: RNA-induced silencing complex; ROS: Reactive oxygen species; RR: Radioresistant; SGPP1: Sphingosine-1-phosphate phosphatase 1;
}

SLUG: Zinc finger protein SNAI2; SNAIL 1: Zinc finger protein SNAI1; SNF2H: SWI/SNF-related matrix-associated actin-dependent regulator of chromatin subfamily A member 5; SOCS1: Suppressor of cytokine signaling protein 1; STAT3: Signal transducer and activator of transcription 3; SUMO: Small Ubiquitin-like Modifier; TME: Tumor microenvironment; Twist $1 /$ 2: Twist family bHLH transcription factor 1/2; VEGF: Vascular endothelial growth factor; XLF: XRCC4-like factor; XPC: Xeroderma pigmentosum complementation group C; ZEB1/2: Zinc finger E-box binding homeobox 1/2

\section{Acknowledgements \\ None.}

\section{Authors' contributions}

DF initiated the study. ML, CH and JR performed the scientific literature search, designed the review structure and wrote the manuscript. ML designed the tables and figures. VP, SS, SKL and DF supervised, helped to revise and edit the manuscript. All authors read and approved the final manuscript.

\section{Funding}

$\mathrm{CH}$ was supported by the Strategic Training in Transdisciplinary Radiation Science for the 21st Century (STARS21) training program funded by the Terry Fox Foundation; Princess Margaret Cancer Centre; the Government of Ontario; and Lawrence, Ila, and William Gifford Scholarship in Radiation Oncology and Surgery. CH was also a recipient of the Queen Elizabeth II Graduate Scholarship in Science and Technology (QEII-GSST) funded by Sunnybrook Health Sciences Centre, University of Toronto, and the Government of Ontario. SKL is a Movember Rising Star award recipient proudly funded by the Movember Foundation (Grants \# RS2014-03, \#D201324), with research funds also provided by the Telus Motorcycle Ride For Dad (Huronia Branch), and a Ministry of Research and Innovation Early Researcher Award. ML was supported by a regional grant (EpiSAVMEN), and by Ms. Suzanne Saulnier. ML and DF were recipient of Ligue contre le cancer grants from committee 22, 35, 44, 49 and 56. ML and DF were also recipient of Canceropôle Grand Ouest (ExomiR project).

\section{Availability of data and materials}

Not applicable.

\section{Ethics approval and consent to participate}

Not applicable.

\section{Consent for publication}

Not applicable.

\section{Competing interests}

The authors declare that they have no competing interests.

\section{Author details}

${ }^{1}$ CRCINA, INSERM, Université d'Angers, Université de Nantes, Nantes, France. ${ }^{2}$ Department of Medical Biophysics, University of Toronto, Toronto, Ontario, Canada. ${ }^{3}$ Biological Sciences, Sunnybrook Research Institute, Sunnybrook Health Sciences Centre, Toronto, Ontario, Canada. Institut de Cancérologie de L'Ouest René Gauducheau, Saint-Herblain, France. ${ }^{5}$ Department of Radiation Oncology, University of Toronto and Odette Cancer Centre, Sunnybrook Health Sciences Centre, Toronto, Ontario, Canada.

Received: 13 December 2019 Accepted: 12 March 2020

Published online: 23 March 2020

\section{References}

1. Bray F, Ferlay J, Soerjomataram I, Siegel RL, Torre LA, Jemal A. Global cancer statistics 2018: GLOBOCAN estimates of incidence and mortality worldwide for 36 cancers in 185 countries. CA Cancer J Clin. 2018;68(6):394-424.

2. Lilja H, Ulmert D, Vickers AJ. Prostate-specific antigen and prostate cancer: prediction, detection and monitoring. Nat Rev Cancer. 2008;8(4):268-78.

3. Martin JM, Supiot S, Berthold DR. Pharmacotherapeutic management of locally advanced prostate cancer: current status. Drugs. 2011;71(8):1019-41.

4. Kurth I, Hein L, Mäbert K, Peitzsch C, Koi L, Cojoc M, et al. Cancer stem cell related markers of radioresistance in head and neck squamous cell carcinoma. Oncotarget. 2015;6(33):34494-509. 
5. Arechaga-Ocampo E, Lopez-Camarillo C, Villegas-Sepulveda N, Gonzalez-De la Rosa CH, Perez-Añorve IX, Roldan-Perez R, et al. Tumor suppressor miR29c regulates radioresistance in lung cancer cells. Tumor Biol. 2017;39(3): 1010428317695010.

6. Ahmed KM, Dong S, Fan M, Li JJ. Nuclear Factor-KB p65 Inhibits MitogenActivated Protein Kinase Signaling Pathway in Radioresistant Breast Cancer Cells. Mol Cancer Res. 2006;4(12):945-55.

7. Hazawa M, Hosokawa Y, Monzen S, Yoshino H, Kashiwakura I. Regulation of DNA damage response and cell cycle in radiation-resistant HL60 myeloid leukemia cells. Oncol Rep. 2012;28(1):55-61.

8. Murata K, Saga R, Monzen S, Tsuruga E, Hasegawa K, Hosokawa Y. Understanding the mechanism underlying the acquisition of radioresistance in human prostate cancer cells. Oncol Lett. 2019;17(6):5830-8.

9. Srinivas US, Tan BWQ, Vellayappan BA, Jeyasekharan AD. ROS and the DNA damage response in cancer. Redox Biol. 2019;25:101084.

10. Connell PP, Hellman S. Advances in Radiotherapy and Implications for the Next Century: A Historical Perspective. Cancer Res. 2009;69(2):383-92.

11. Redza-Dutordoir M, Averill-Bates DA. Activation of apoptosis signalling pathways by reactive oxygen species. Biochim Biophys Acta BBA Mol Cell Res. 2016;1863(12):2977-92

12. Chan N, Bristow RG. "Contextual" synthetic lethality and/or loss of heterozygosity: tumor hypoxia and modification of DNA repair. Clin Cancer Res Off J Am Assoc Cancer Res. 2010;16(18):4553-60.

13. Padhani AR, Krohn KA, Lewis JS, Alber M. Imaging oxygenation of human tumours. Eur Radiol. 2007;17(4):861-72.

14. Potiron VA, Abderrahmani R, Clément-Colmou K, Marionneau-Lambot S, Oullier T, Paris F, et al. Improved Functionality of the Vasculature during Conventionally Fractionated Radiation Therapy of Prostate Cancer. PLoS One. 2013;8(12):e84076.

15. Supiot $\mathrm{S}$, Rousseau C, Dore M, Chèze-Le-Rest C, Kandel-Aznar C, Potiron V et al. Reoxygenation during radiotherapy in intermediate-risk prostate cancer. Radiother Oncol. 2019;133:16-9.

16. Guipaud O, Jaillet C, Clément-Colmou K, François A, Supiot S, Milliat F. The importance of the vascular endothelial barrier in the immune-inflammatory response induced by radiotherapy. Br J Radiol. 2018;91(1089):20170762.

17. Garcia-Barros M, Paris F, Cordon-Cardo C, Lyden D, Rafii S, HaimovitzFriedman A, et al. Tumor response to radiotherapy regulated by endothelial cell apoptosis. Science. 2003;300(5622):1155-9.

18. Chen F-H, Chiang C-S, Wang C-C, Tsai C-S, Jung S-M, Lee C-C, et al. Radiotherapy Decreases Vascular Density and Causes Hypoxia with Macrophage Aggregation in TRAMP-C1 Prostate Tumors. Clin Cancer Res Off J Am Assoc Cancer Res. 2009;15(5):1721-9.

19. Barker HE, Paget JTE, Khan AA, Harrington KJ. The Tumour Microenvironment after Radiotherapy: Mechanisms of Resistance and Recurrence. Nat Rev Cancer. 2015;15(7):409-25.

20. Liu Y, Dong Y, Kong L, Shi F, Zhu H, Yu J. Abscopal effect of radiotherapy combined with immune checkpoint inhibitors. J Hematol OncolJ Hematol Oncol. 2018;11(1):104.

21. Mitani T, Yamaji R, Higashimura $Y$, Harada N, Nakano $Y$, Inui H. Hypoxia enhances transcriptional activity of androgen receptor through hypoxiainducible factor-1a in a low androgen environment. J Steroid Biochem Mol Biol. 2011;123(1-2):58-64.

22. Tan ME, Li J, Xu HE, Melcher K, Yong E. Androgen receptor: structure, role in prostate cancer and drug discovery. Acta Pharmacol Sin. 2015;36(1):3-23.

23. Yin Y, Li R, Xu K, Ding S, Li J, Baek G, et al. Androgen Receptor Variants Mediate DNA Repair after Prostate Cancer Irradiation. Cancer Res. 2017;77(18):4745-54.

24. Yao M, Rogers L, Suchowerska N, Choe D, Al-Dabbas MA, Narula RS, et al. Sensitization of prostate cancer to radiation therapy: Molecules and pathways to target. Radiother Oncol. 2018;128(2):283-300.

25. Locke JA, Pra AD, Supiot S, Warde P, Bristow RG. Synergistic action of image-guided radiotherapy and androgen deprivation therapy. Nat Rev Urol. 2015;12(4):193-204.

26. Chua MLK, Bristow RG. Testosterone in Androgen Receptor Signaling and DNA Repair: Enemy or Frenemy? Clin Cancer Res. 2016;22(13):3124-6.

27. Mahajan K, Coppola D, Rawal B, Chen YA, Lawrence HR, Engelman RW, et al. Ack1-mediated androgen receptor phosphorylation modulates radiation resistance in castration-resistant prostate cancer. J Biol Chem. 2012;287(26): 22112-22.

28. Spratt DE, Evans MJ, Davis BJ, Doran MG, Lee MX, Shah N, et al. Androgen Receptor Upregulation Mediates Radioresistance after lonizing Radiation. Cancer Res. 2015;75(22):4688-96.
29. Czochor JR, Glazer PM. microRNAs in Cancer Cell Response to lonizing Radiation. Antioxid Redox Signal. 2014;21(2):293-312.

30. Korpela E, Vesprini D, Liu SK. MicroRNA in radiotherapy: miRage or miRador? Br J Cancer. 2015:112(5):777-82.

31. $\mathrm{Hu} H$, Gatti RA. MicroRNAs: new players in the DNA damage response. J Mol Cell Biol. 2011;3(3):151-8.

32. Gandellini $P$, Rancati T, Valdagni R, Zaffaroni N. miRNAs in tumor radiation response: bystanders or participants? Trends Mol Med. 2014;20(9):529-39.

33. Ni J, Bucci J, Chang L, Malouf D, Graham P, Li Y. Targeting MicroRNAs in Prostate Cancer Radiotherapy. Theranostics. 2017;7(13):3243-59.

34. Simone NL, Soule BP, Ly D, Saleh AD, Savage JE, DeGraff W, et al. lonizing Radiation-Induced Oxidative Stress Alters miRNA Expression. PLoS One. 2009;4(7):e6377.

35. Templin T, Paul S, Amundson SA, Young EF, Barker CA, Wolden SL, et al. Radiation-induced micro-RNA expression changes in peripheral blood cells of radiotherapy patients. Int J Radiat Oncol Biol Phys. 2011;80(2):549-57.

36. Bartel DP. MicroRNAs: genomics, biogenesis, mechanism, and function. Cell. 2004;116(2):281-97.

37. Lin S, Gregory RI. MicroRNA biogenesis pathways in cancer. Nat Rev Cancer. 2015;15(6):321-33.

38. Eulalio A, Huntzinger E, Izaurralde E. Getting to the Root of miRNA-Mediated Gene Silencing. Cell. 2008;132(1):9-14.

39. Peng $Y$, Croce CM. The role of MicroRNAs in human cancer. Signal Transduct Target Ther. 2016;1:15004.

40. Huang $X$, Taeb S, Jahangiri S, Emmenegger U, Tran E, Bruce J, et al. miRNA95 mediates radioresistance in tumors by targeting the sphingolipid phosphatase SGPP1. Cancer Res. 2013;73(23):6972-86.

41. Leung C-M, Li S-C, Chen T-W, Ho M-R, Hu L-Y, Liu W-S, et al. Comprehensive microRNA profiling of prostate cancer cells after ionizing radiation treatment. Oncol Rep. 2014;31(3):1067-78.

42. Xu C-G, Yang M-F, Fan J-X, Wang W. MiR-30a and miR-205 are downregulated in hypoxia and modulate radiosensitivity of prostate cancer cells by inhibiting autophagy via TP53INP1. Eur Rev Med Pharmacol Sci. 2016:20(8):1501-8

43. John-Aryankalayil M, Palayoor ST, Makinde AY, Cerna D, Simone CB, Falduto MT, et al. Fractionated Radiation Alters Oncomir and Tumor Suppressor miRNAs in Human Prostate Cancer Cells. Radiat Res. 2012;178(3):105-17.

44. Wang F, Mao A, Tang J, Zhang Q, Yan J, Wang Y, et al. microRNA-16-5p enhances radiosensitivity through modulating Cyclin D1/E1-pRb-E2F1 pathway in prostate cancer cells. J Cell Physiol. 2019:234(8):13182-90.

45. Tao Z, Xu S, Ruan H, Wang T, Song W, Qian L, et al. MiR-195/-16 Family Enhances Radiotherapy via T Cell Activation in the Tumor Microenvironment by Blocking the PD-L1 Immune Checkpoint. Cell Physiol Biochem. 2018;48(2):801-14.

46. Josson S, Sung S-Y, Lao K, Chung LWK, Johnstone PAS. Radiation modulation of microRNA in prostate cancer cell lines. Prostate. 2008;68(15): 1599-606.

47. Mao A, Liu Y, Wang Y, Zhao Q, Zhou X, Sun C, et al. miR-449a enhances radiosensitivity through modulating $\mathrm{pRb} / \mathrm{E} 2 \mathrm{~F} 1$ in prostate cancer cells. Tumour Biol J Int Soc Oncodevelopmental Biol Med. 2016;37(4):4831-40.

48. Mao A, Zhao Q, Zhou X, Sun C, Si J, Zhou R, et al. MicroRNA-449a enhances radiosensitivity by downregulation of c-Myc in prostate cancer cells. Sci Rep. 2016;6:27346.

49. Li B, Shi X-B, Nori D, Chao CKS, Chen AM, Valicenti R, et al. Down-regulation of microRNA $106 \mathrm{~b}$ is involved in p21-mediated cell cycle arrest in response to radiation in prostate cancer cells. Prostate. 2011;71(6):567-74.

50. McDermott N, Meunier A, Wong S, Buchete V, Marignol L. Profiling of a panel of radioresistant prostate cancer cells identifies deregulation of key miRNAs. Clin Transl Radiat Oncol. 2017;2:63-8.

51. Mercatelli N, Coppola V, Bonci D, Miele F, Costantini A, Guadagnoli M, et al. The Inhibition of the Highly Expressed Mir-221 and Mir-222 Impairs the Growth of Prostate Carcinoma Xenografts in Mice. PLoS One. 2008;3(12): e4029.

52. Xu Z, Zhang $Y$, Ding J, Hu W, Tan C, Wang M, et al. miR-17-3p Downregulates Mitochondrial Antioxidant Enzymes and Enhances the Radiosensitivity of Prostate Cancer Cells. Mol Ther Nucleic Acids. 2018; 13:64-77

53. Mueller AC, Sun D, Dutta A. The miR-99 family regulates the DNA damage response through its target SNF2H. Oncogene. 2013;32(9):1164-72.

54. Gong P, Zhang T, He D, Hsieh J-T. MicroRNA-145 Modulates Tumor Sensitivity to Radiation in Prostate Cancer. Radiat Res. 2015;184(6):630-8. 
55. Hatano K, Kumar B, Zhang Y, Coulter JB, Hedayati M, Mears B, et al. A functional screen identifies miRNAs that inhibit DNA repair and sensitize prostate cancer cells to ionizing radiation. Nucleic Acids Res. 2015;43(8): 4075-86.

56. Yaman Agaoglu F, Kovancilar M, Dizdar Y, Darendeliler E, Holdenrieder S, Dalay N, et al. Investigation of miR-21, miR-141, and miR-221 in blood circulation of patients with prostate cancer. Tumour Biol J Int Soc Oncodevelopmental Biol Med. 2011;32(3):583-8.

57. Chen Z-H, Zhang G-L, Li H-R, Luo J-D, Li Z-X, Chen G-M, et al. A panel of five circulating microRNAs as potential biomarkers for prostate cancer. Prostate. 2012;72(13):1443-52.

58. Porzycki P, Ciszkowicz E, Semik M, Tyrka M. Combination of three miRNA (miR-141, miR-21, and miR-375) as potential diagnostic tool for prostate cancer recognition. Int Urol Nephrol. 2018;50(9):1619-26.

59. Richardsen E, Andersen S, Melbø-Jørgensen C, Rakaee M, Ness N, Al-Saad S, et al. MicroRNA 141 is associated to outcome and aggressive tumor characteristics in prostate cancer. Sci Rep. 2019;23:9.

60. Liu C, Liu R, Zhang D, Deng Q, Liu B, Chao H-P, et al. MicroRNA-141 suppresses prostate cancer stem cells and metastasis by targeting a cohort of pro-metastasis genes. Nat Commun. 2017:8(1):1-14.

61. Johnson SM, Grosshans $H$, Shingara J, Byrom $M$, Jarvis R, Cheng A, et al. RAS is regulated by the let-7 microRNA family. Cell. 2005;120(5):635-47.

62. Sampson VB, Rong NH, Han J, Yang Q, Aris V, Soteropoulos P, et al. MicroRNA let-7a down-regulates MYC and reverts MYC-induced growth in Burkitt lymphoma cells. Cancer Res. 2007;67(20):9762-70.

63. Fernandes RC, Hickey TE, Tilley WD, Selth LA. Interplay between the androgen receptor signaling axis and microRNAs in prostate cancer. Endocr Relat Cancer. 2019;26(5):R237-57.

64. Hu B, Wang $X$, Hu S, Ying $X$, Wang P, Zhang $X$, et al. miR-21-mediated Radioresistance Occurs via Promoting Repair of DNA Double Strand Breaks. J Biol Chem. 2017;292(8):3531-40

65. Ribas J, Lupold SE. The transcriptional regulation of miR-21, its multiple transcripts, and their implication in prostate cancer. Cell Cycle. 2010;9(5): 923-9.

66. Ribas J, Ni X, Haffner M, Wentzel EA, Salmasi AH, Chowdhury WH, et al. miR21: an androgen receptor-regulated microRNA that promotes hormonedependent and hormone-independent prostate cancer growth. Cancer Res. 2009:69(18):7165-9.

67. Yentrapalli R, Merl-Pham J, Azimzadeh O, Mutschelknaus L, Peters C, Hauck $\mathrm{SM}$, et al. Quantitative changes in the protein and miRNA cargo of plasma exosome-like vesicles after exposure to ionizing radiation. Int J Radiat Biol. 2017;93(6):569-80

68. El Bezawy R, Tinelli S, Tortoreto M, Doldi V, Zuco V, Folini M, et al. miR-205 enhances radiation sensitivity of prostate cancer cells by impairing DNA damage repair through PKC $\varepsilon$ and ZEB1 inhibition. J Exp Clin Cancer Res CR. 2019;38(1):51.

69. Wanner G, Mayer C, Kehlbach R, Rodemann HP, Dittmann K. Activation of protein kinase Cepsilon stimulates DNA-repair via epidermal growth factor receptor nuclear accumulation. Radiother Oncol J Eur Soc Ther Radio Oncol. 2008 Mar;86(3):383-90

70. El Bezawy R, Cominetti D, Fenderico N, Zuco V, Beretta GL, Dugo M, et al, miR-875-5p counteracts epithelial-to-mesenchymal transition and enhances radiation response in prostate cancer through repression of the EGFR-ZEB1 axis. Cancer Lett. 2017;395:53-62.

71. Polkinghorn WR, Parker JS, Lee MX, Kass EM, Spratt DE, laquinta PJ, et al. Androgen receptor signaling regulates DNA repair in prostate cancers. Cancer Discov. 2013;3(11):1245-53.

72. Larne O, Hagman Z, Lilja H, Bjartell A, Edsjö A, Ceder Y. miR-145 suppress the androgen receptor in prostate cancer cells and correlates to prostate cancer prognosis. Carcinogenesis. 2015;36(8):858-66.

73. Kanwal R, Plaga AR, Liu X, Shukla GC, Gupta S. MicroRNAs in prostate cancer: Functional role as biomarkers. Cancer Lett. 2017:407:9-20.

74. Östling P, Leivonen S-K, Aakula A, Kohonen P, Mäkelä R, Hagman Z, et al. Systematic analysis of microRNAs targeting the androgen receptor in prostate cancer cells. Cancer Res. 2011;71(5):1956-67.

75. Sikand K, Slaibi JE, Singh R, Slane SD, Shukla GC. miR 488* inhibits androgen receptor expression in prostate carcinoma cells. Int J Cancer. 2011;129(4): 810-9.

76. Sancar A, Lindsey-Boltz LA, Ünsal-Kaçmaz K, Linn S. Molecular Mechanisms of Mammalian DNA Repair and the DNA Damage Checkpoints. Annu Rev Biochem. 2004;73(1):39-85.
77. Takeshita F, Patrawala L, Osaki M, Takahashi R, Yamamoto Y, Kosaka N, et al. Systemic delivery of synthetic microRNA-16 inhibits the growth of metastatic prostate tumors via downregulation of multiple cell-cycle genes. Mol Ther J Am Soc Gene Ther. 2010;18(1):181-7.

78. Zhang Z, Shao L, Wang Y, Luo X. MicroRNA-501-3p restricts prostate cancer growth through regulating cell cycle-related and expression-elevated protein in tumor/cyclin D1 signaling. Biochem Biophys Res Commun. 2019;509(3):746-52.

79. Dong Q, Meng P, Wang T, Qin W, Qin W, Wang F, et al. MicroRNA Let-7a Inhibits Proliferation of Human Prostate Cancer Cells In Vitro and In Vivo by Targeting E2F2 and CCND2. PLoS One. 2010;5(4):e10147.

80. Zheng Y, Zhu C, Ma L, Shao P, Qin C, Li P, et al. miRNA-154-5p Inhibits Proliferation, Migration and Invasion by Targeting E2F5 in Prostate Cancer Cell Lines. Urol Int. 2017:98(1):102-10.

81. Zhu C, Shao P, Bao M, Li P, Zhou H, Cai H, et al. miR-154 inhibits prostate cancer cell proliferation by targeting CCND2. Urol Oncol Semin Orig Investig. 2014;32(1):31.e9-31.e16.

82. Tang Y, Cui Y, Li Z, Jiao Z, Zhang Y, He Y, et al. Radiation-induced miR-208a increases the proliferation and radioresistance by targeting p21 in human lung cancer cells. J Exp Clin Cancer Res. 2016;35(1):7.

83. Lynch SM, McKenna MM, Walsh CP, McKenna DJ. miR-24 regulates CDKN1B/ p27 expression in prostate cancer. Prostate. 2016;76(7):637-48.

84. Galardi S, Mercatelli N, Giorda E, Massalini S, Frajese GV, Ciafrè SA, et al. miR221 and miR-222 Expression Affects the Proliferation Potential of Human Prostate Carcinoma Cell Lines by Targeting p27Kip1. J Biol Chem. 2007; 282(32):23716-24

85. Duan X-M, Liu X-N, Li Y-X, Cao Y-Q, Silayiding A, Zhang R-K, et al. MicroRNA498 promotes proliferation, migration, and invasion of prostate cancer cells and decreases radiation sensitivity by targeting PTEN. Kaohsiung J Med Sci. 2019;35(11):659-71.

86. Pashaei E, Pashaei E, Ahmady M, Ozen M, Aydin N. Meta-analysis of miRNA expression profiles for prostate cancer recurrence following radical prostatectomy. PLoS One. 2017;12(6):e0179543.

87. Eriksson D, Stigbrand T. Radiation-induced cell death mechanisms. Tumour Biol J Int Soc Oncodevelopmental Biol Med. 2010 Aug;31(4):363-72.

88. Bromfield GP, Meng A, Warde P, Bristow RG. Cell death in irradiated prostate epithelial cells: role of apoptotic and clonogenic cell kill. Prostate Cancer Prostatic Dis. 2003;6(1):73-85.

89. Ye C, Sun N, Ma Y, Zhao Q, Zhang Q, Xu C, et al. MicroRNA-145 contributes to enhancing radiosensitivity of cervical cancer cells. FEBS Lett. 2015;589(6):702-9.

90. Cho S, Cinghu S, Yu J-R, Park W-Y. Helicase-like transcription factor confers radiation resistance in cervical cancer through enhancing the DNA damage repair capacity. J Cancer Res Clin Oncol. 2011;137(4):629-37.

91. Wang C, Tao W, Ni S, Chen Q, Zhao Z, Ma L, et al. Tumor-suppressive microRNA-145 induces growth arrest by targeting SENP1 in human prostate cancer cells. Cancer Sci. 2015;106(4):375-82.

92. Cheng J, Bawa T, Lee P, Gong L, Yeh ETH. Role of Desumoylation in the Development of Prostate Cancer. Neoplasia. 2006;8(8):667-76.

93. Liao H, Xiao Y, Hu Y, Xiao Y, Yin Z, Liu L. microRNA-32 induces radioresistance by targeting DAB2IP and regulating autophagy in prostate cancer cells. Oncol Lett. 2015;10(4):2055-62.

94. Kong Z, Xie D, Boike T, Raghavan P, Burma S, Chen DJ, et al. Downregulation of human DAB2IP gene expression in prostate cancer cells results in resistance to ionizing radiation. Cancer Res. 2010;70(7):2829-39.

95. Bao B, Ahmad A, Kong D, Ali S, Azmi AS, Li Y, et al. Hypoxia induced aggressiveness of prostate cancer cells is linked with deregulated expression of VEGF, IL-6 and miRNAs that are attenuated by CDF. PLoS One. 2012;7(8):e43726.

96. Supiot S, Rousseau C, Dore M, Cheze-Le-Rest C, Kandel-Aznar C, Potiron V, et al. Evaluation of tumor hypoxia prior to radiotherapy in intermediate-risk prostate cancer using 18F-fluoromisonidazole PET/CT: a pilot study. Oncotarget. 2018;9(11):10005-15.

97. Chung AS, Lee J, Ferrara N. Targeting the tumour vasculature: insights from physiological angiogenesis. Nat Rev Cancer. 2010;10(7):505-14.

98. Rupaimoole R, Calin GA, Lopez-Berestein G, Sood AK. miRNA Deregulation in Cancer Cells and the Tumor Microenvironment. Cancer Discov. 2016;6(3):235-46.

99. Jung H-Y, Fattet L, Yang J. Molecular Pathways: Linking Tumor Microenvironment to Epithelial-Mesenchymal Transition in Metastasis. Clin Cancer Res Off J Am Assoc Cancer Res. 2015:21(5):962-8.

100. Wang W, Liu M, Guan Y, Wu Q. Hypoxia-Responsive Mir-301a and Mir-301b Promote Radioresistance of Prostate Cancer Cells via Downregulating NDRG2. Med Sci Monit Int Med J Exp Clin Res. 2016;22:2126-32. 
101. Kim M-J, Lim J, Yang Y, Lee M-S, Lim J-S. N-myc downstream-regulated gene 2 (NDRG2) suppresses the epithelial-mesenchymal transition (EMT) in breast cancer cells via STAT3/Snail signaling. Cancer Lett. 2014;354(1):33-42.

102. Gu H, Liu M, Ding C, Wang X, Wang R, Wu X, et al. Hypoxia-responsive miR124 and miR-144 reduce hypoxia-induced autophagy and enhance radiosensitivity of prostate cancer cells via suppressing PIM1. Cancer Med. 2016;5(6):1174-82

103. Zhao B, Liu L, Mao J, Zhang Z, Wang Q, Li Q. PIM1 mediates epithelialmesenchymal transition by targeting Smads and c-Myc in the nucleus and potentiates clear-cell renal-cell carcinoma oncogenesis. Cell Death Dis. 2018; 9(3):307.

104. Hu W, Fan C, Jiang P, Ma Z, Yan X, Di S, et al. Emerging role of N-myc downstream-regulated gene 2 (NDRG2) in cancer. Oncotarget. 2016;7(1): 209-23

105. Wu T, Dai Y. Tumor microenvironment and therapeutic response. Cancer Lett. 2017;387:61-8.

106. Menon H, Ramapriyan R, Cushman TR, Verma V, Kim HH, Schoenhals JE, et al. Role of Radiation Therapy in Modulation of the Tumor Stroma and Microenvironment. Front Immunol. 2019;10:193.

107. Chaiswing L, Weiss HL, Jayswal RD, St. Clair DK, Kyprianou N. Profiles of Radioresistance Mechanisms in Prostate Cancer. Crit Rev Oncog. 2018;23(12):39-67.

108. Chou J, Shahi P, Werb Z. microRNA-mediated regulation of the tumor microenvironment. Cell Cycle. 2013 Oct 15;12(20):3262-71.

109. Kuninty PR, Schnittert J, Storm G, Prakash J. MicroRNA Targeting to Modulate Tumor Microenvironment. Front Oncol. 2016;6:3.

110. Nishida N, Yano H, Nishida T, Kamura T, Kojiro M. Angiogenesis in Cancer. Vasc Health Risk Manag. 2006 Sep;2(3):213-9.

111. Lou W, Liu J, Gao Y, Zhong G, Chen D, Shen J, et al. MicroRNAs in cancer metastasis and angiogenesis. Oncotarget. 2017 Dec 11;8(70):115787-802.

112. Plummer PN, Freeman R, Taft RJ, Vider J, Sax M, Umer BA, et al. MicroRNAs Regulate Tumor Angiogenesis Modulated by Endothelial Progenitor Cells. Cancer Res. 2013 Jan 1;73(1):341-52.

113. Wang $Y$, Wang $L$, Chen $C$, Chu $X$. New insights into the regulatory role of microRNA in tumor angiogenesis and clinical implications. Mol Cancer. 2018 Feb 7;17(1):22.

114. Lin Z-Y, Chen G, Zhang Y-Q, He H-C, Liang Y-X, Ye J-H, et al. MicroRNA-30d promotes angiogenesis and tumor growth via MYPT1/C-JUN/VEGFA pathway and predicts aggressive outcome in prostate cancer. Mol Cancer. 2017;16(1):48.

115. Guan B, Wu K, Zeng J, Xu S, Mu L, Gao Y, et al. Tumor-suppressive microRNA-218 inhibits tumor angiogenesis via targeting the mTOR component RICTOR in prostate cancer. Oncotarget. 2016;8(5):8162-72.

116. Gajewski TF, Schreiber H, Fu Y-X. Innate and adaptive immune cells in the tumor microenvironment. Nat Immunol. 2013;14(10):1014-22.

117. Juneja VR, McGuire KA, Manguso RT, LaFleur MW, Collins N, Haining WN, et al. PD-L1 on tumor cells is sufficient for immune evasion in immunogenic tumors and inhibits CD8 T cell cytotoxicity. J Exp Med. 2017; 214(4):895-904

118. Lo U-G, Lee C-F, Lee M-S, Hsieh J-T. The Role and Mechanism of Epithelialto-Mesenchymal Transition in Prostate Cancer Progression. Int J Mol Sci. 2017;30:18(10)

119. Hanahan D, Weinberg RA. Hallmarks of Cancer: The Next Generation. Cell. 2011;144(5):646-74.

120. Sekhon K, Bucay N, Majid S, Dahiya R, Saini S. MicroRNAs and epithelialmesenchymal transition in prostate cancer. Oncotarget. 2016;7(41):67597611.

121. Ren D, Wang M, Guo W, Huang S, Wang Z, Zhao X, et al. Double-negative feedback loop between ZEB2 and miR-145 regulates epithelialmesenchymal transition and stem cell properties in prostate cancer cells. Cell Tissue Res. 2014;358(3):763-78.

122. Guo W, Ren D, Chen X, Tu X, Huang S, Wang M, et al. HEF1 promotes epithelial mesenchymal transition and bone invasion in prostate cancer under the regulation of microRNA-145. J Cell Biochem. 2013;114(7):1606-15.

123. Gandellini P, Profumo V, Casamichele A, Fenderico N, Borrelli S, Petrovich G, et al. miR-205 regulates basement membrane deposition in human prostate: implications for cancer development. Cell Death Differ. 2012;19(11): 1750-60.

124. Gandellini P, Folini M, Longoni N, Pennati M, Binda M, Colecchia M, et al. miR-205 Exerts tumor-suppressive functions in human prostate through down-regulation of protein kinase Cepsilon. Cancer Res. 2009;69(6):2287-95.
125. Zhang P, Wang L, Rodriguez-Aguayo C, Yuan Y, Debeb BG, Chen D, et al. miR-205 acts as a tumour radiosensitizer by targeting ZEB1 and Ubc13. Nat Commun. 2014;5:5671.

126. Wang Y, Yuan JL, Zhang YT, Ma JJ, Xu P, Shi CH, et al. Inhibition of Both EGFR and IGF1R Sensitized Prostate Cancer Cells to Radiation by Synergistic Suppression of DNA Homologous Recombination Repair. PLoS One. 2013; 8(8):e68784.

127. Ru P, Steele R, Newhall P, Phillips NJ, Toth K, Ray RB. miRNA-29b Suppresses Prostate Cancer Metastasis by Regulating Epithelial-Mesenchymal Transition Signaling. Mol Cancer Ther. 2012;11(5):1166-73.

128. Banyard J, Chung I, Wilson AM, Vetter G, Le Béchec A, Bielenberg DR, et al. Regulation of epithelial plasticity by miR-424 and miR-200 in a new prostate cancer metastasis model. Sci Rep. 2013:3:3151.

129. Bracken CP, Gregory PA, Khew-Goodall Y, Goodall GJ. The role of microRNAs in metastasis and epithelial-mesenchymal transition. Cell Mol Life Sci CMLS. 2009;66(10):1682-99.

130. Kong D, Li Y, Wang Z, Banerjee S, Ahmad A, Kim H-RC, et al. miR-200 regulates PDGF-D-mediated epithelial-mesenchymal transition, adhesion, and invasion of prostate cancer cells. Stem Cells Dayt Ohio. 2009;27(8):1712-21.

131. Zhu C, Li J, Cheng G, Zhou H, Tao L, Cai H, et al. miR-154 inhibits EMT by targeting HMGA2 in prostate cancer cells. Mol Cell Biochem. 2013;379(1-2):69-75.

132. Mulholland DJ, Tran LM, Li Y, Cai H, Morim A, Wang S, et al. Cell Autonomous Role of PTEN in Regulating Castration-Resistant Prostate Cancer Growth. Cancer Cell. 2011;19(6):792-804

133. He E, Pan F, Li G, Li J. Fractionated Ionizing Radiation Promotes EpithelialMesenchymal Transition in Human Esophageal Cancer Cells through PTEN Deficiency-Mediated Akt Activation. PLoS One. 2015;10(5):e0126149.

134. Shao N, Ma G, Zhang J, Zhu W. miR-221-5p enhances cell proliferation and metastasis through post-transcriptional regulation of SOCS1 in human prostate cancer. BMC Urol. 2018;18(1):14.

135. Chang L, Graham P, Hao J, Ni J, Deng J, Bucci J, et al. Cancer stem cells and signaling pathways in radioresistance. Oncotarget. 2015;7(10):11002-17.

136. Xiao W, Graham PH, Power CA, Hao J, Kearsley JH, Li Y. CD44 is a biomarker associated with human prostate cancer radiation sensitivity. Clin Exp Metastasis. 2012;29(1):1-9.

137. Rane JK, Erb HHH, Nappo G, Mann VM, Simms MS, Collins AT, et al. Inhibition of the glucocorticoid receptor results in an enhanced miR-99a/ 100-mediated radiation response in stem-like cells from human prostate cancers. Oncotarget. 2016;7(32):51965-80.

138. van Niel G, D'Angelo G, Raposo G. Shedding light on the cell biology of extracellular vesicles. Nat Rev Mol Cell Biol. 2018;19(4):213.

139. Raposo G, Stoorvogel W. Extracellular vesicles: Exosomes, microvesicles, and friends. J Cell Biol. 2013;200(4):373-83.

140. Valadi H, Ekström K, Bossios A, Sjöstrand M, Lee JJ, Lötvall JO. Exosomemediated transfer of mRNAs and microRNAs is a novel mechanism of genetic exchange between cells. Nat Cell Biol. 2007;9(6):654-9.

141. Melo SA, Sugimoto H, O'Connell JT, Kato N, Villanueva A, Vidal A, et al. Cancer Exosomes Perform Cell-Independent MicroRNA Biogenesis and Promote Tumorigenesis. Cancer Cell. 2014;26(5):707-21.

142. Ruivo CF, Adem B, Silva M, Melo SA. The Biology of Cancer Exosomes: Insights and New Perspectives. Cancer Res. 2017;77(23):6480-8.

143. Guduric-Fuchs J, O'Connor A, Camp B, O'Neill CL, Medina RJ, Simpson DA. Selective extracellular vesicle-mediated export of an overlapping set of microRNAs from multiple cell types. BMC Genomics. 2012;13(1):357.

144. Cheng L, Sharples RA, Scicluna BJ, Hill AF. Exosomes provide a protective and enriched source of miRNA for biomarker profiling compared to intracellular and cell-free blood. J Extracell Vesicles. 2014;3(1):23743.

145. Hessvik NP, Sandvig K, Llorente A. Exosomal miRNAs as Biomarkers for Prostate Cancer. Front Genet. 2013;4:36.

146. Malla B, Aebersold DM, Dal PA. Protocol for serum exosomal miRNAs analysis in prostate cancer patients treated with radiotherapy. J Transl Med. 2018;16(1):223.

147. Yang $Y$, Guo J-X, Shao Z-Q. miR-21 targets and inhibits tumor suppressor gene PTEN to promote prostate cancer cell proliferation and invasion: An experimental study. Asian Pac J Trop Med. 2017;10(1):87-91.

148. Li T, Li D, Sha J, Sun P, Huang Y. MicroRNA-21 directly targets MARCKS and promotes apoptosis resistance and invasion in prostate cancer cells. Biochem Biophys Res Commun. 2009:383(3):280-5.

149. Schramedei K, Mörbt N, Pfeifer G, Läuter J, Rosolowski M, Tomm JM, et al. MicroRNA-21 targets tumor suppressor genes ANP32A and SMARCA4. Oncogene. 2011;30(26):2975-85. 
150. Yu Q, Li P, Weng M, Wu S, Zhang Y, Chen X, et al. Nano-Vesicles are a Potential Tool to Monitor Therapeutic Efficacy of Carbon Ion Radiotherapy in Prostate Cancer. J Biomed Nanotechnol. 2018;14(1):168-78.

151. Gao Q, Zheng J. microRNA-323 upregulation promotes prostate cancer growth and docetaxel resistance by repressing p73. Biomed Pharmacother. 2018;97:528-34.

152. Gao Q, Yao X, Zheng J. MiR-323 Inhibits Prostate Cancer Vascularization Through Adiponectin Receptor. Cell Physiol Biochem. 2015:36(4):1491-8.

153. Josson S, Gururajan M, Sung SY, Hu P, Shao C, Zhau HE, et al. Stromal fibroblast-derived miR-409 promotes epithelial-to-mesenchymal transition and prostate tumorigenesis. Oncogene. 2015;34(21):2690-9.

154. Wang S, Wang X, Li J, Meng S, Liang Z, Xu X, et al. C-Met, CREB1 and EGFR are involved in miR-493-5p inhibition of EMT via AKT/GSK-3 $\beta / S$ nail signaling in prostate cancer. Oncotarget. 2017:8(47):82303-13.

155. Shen P, Chen X, Liao Y, Chen N, Zhou Q, Wei Q, et al. MicroRNA-494-3p targets CXCR4 to suppress the proliferation, invasion, and migration of prostate cancer. Prostate. 2014;74(7):756-67.

156. Du Y, Zhu H, Liu X, Wang L, Ning J, Xiao C. MiR-543 Promotes Proliferation and Epithelial-Mesenchymal Transition in Prostate Cancer via Targeting RKIP. Cell Physiol Biochem. 2017;41(3):1135-46.

157. Ni J, Bucci J, Malouf D, Knox M, Graham P, Li Y. Exosomes in Cancer Radioresistance. Front Oncol. 2019;9:869.

158. Malla B, Zaugg K, Vassella E, Aebersold DM, Dal PA. Exosomes and Exosomal MicroRNAs in Prostate Cancer Radiation Therapy. Int J Radiat Oncol Biol Phys. 2017;98(5):982-95.

159. Al-Mayah AHJ, Irons SL, Pink RC, Carter DRF, Kadhim MA. Possible role of exosomes containing RNA in mediating nontargeted effect of ionizing radiation. Radiat Res. 2012;177(5):539-45.

160. Al-Mayah A, Bright S, Chapman K, Irons S, Luo P, Carter D, et al. The nontargeted effects of radiation are perpetuated by exosomes. Mutat Res. 2015; 772:38-45.

161. Mutschelknaus L, Peters C, Winkler K, Yentrapalli R, Heider T, Atkinson MJ, et al. Exosomes Derived from Squamous Head and Neck Cancer Promote Cell Survival after lonizing Radiation. PLoS One. 2016;11(3):e0152213.

162. Arscott WT, Tandle AT, Zhao S, Shabason JE, Gordon IK, Schlaff CD, et al. Ionizing radiation and glioblastoma exosomes: implications in tumor biology and cell migration. Transl Oncol. 2013;6(6):638-48.

163. Ahmed HU, El-Shater Bosaily A, Brown LC, Gabe R, Kaplan R, Parmar MK et al. Diagnostic accuracy of multi-parametric MRI and TRUS biopsy in prostate cancer (PROMIS): a paired validating confirmatory study. Lancet Lond Engl. 2017;389(10071):815-22.

164. Loeb S, Vellekoop A, Ahmed HU, Catto J, Emberton M, Nam R, et al. Systematic review of complications of prostate biopsy. Eur Urol. 2013;64(6): 876-92.

165. McKiernan J, Donovan MJ, O’Neill V, Bentink S, Noerholm M, Belzer S, et al. A Novel Urine Exosome Gene Expression Assay to Predict High-grade Prostate Cancer at Initial Biopsy. JAMA Oncol. 2016;2(7):882-9.

166. Hessels D, Klein Gunnewiek JMT, van Oort I, Karthaus HFM, van Leenders GJL, van Balken B, et al. DD3(PCA3)-based molecular urine analysis for the diagnosis of prostate cancer. Eur Urol. 2003;44(1):6-8

167. Roobol MJ, Schroder FH, van Leeuwen P, Wolters T, van den Bergh RCN, van Leenders GJLH, et al. Performance of the prostate cancer antigen 3 (PCA3) gene and prostate-specific antigen in prescreened men: exploring the value of PCA3 for a first-line diagnostic test. Eur Urol. 2010;58(4):475-81.

168. Vickers AJ, Cronin AM, Aus G, Pihl C-G, Becker C, Pettersson K et al. A panel of kallikrein markers can reduce unnecessary biopsy for prostate cancer: data from the European Randomized Study of Prostate Cancer Screening in Goteborg. Sweden BMC Med. 2008;6:19.

169. Vickers A, Cronin A, Roobol M, Savage C, Peltola M, Pettersson K, et al. Reducing unnecessary biopsy during prostate cancer screening using a four-kallikrein panel: an independent replication. J Clin Oncol Off J Am Soc Clin Oncol. 2010;28(15):2493-8.

170. Hoey C, Liu SK. Circulating blood miRNAs for prostate cancer risk stratification: miRroring the underlying tumor biology with liquid biopsies. Res Rep Urol. 2019;11:29-42.

171. Schwarzenbach H, Nishida N, Calin GA, Pantel K. Clinical relevance of circulating cell-free microRNAs in cancer. Nat Rev Clin Oncol. 2014;11(3): $145-56$

172. Alhasan AH, Scott AW, Wu JJ, Feng G, Meeks JJ, Thaxton CS, et al. Circulating microRNA signature for the diagnosis of very high-risk prostate cancer. Proc Natl Acad Sci U S A. 2016;113(38):10655-60.
173. Hoey C, Ahmed M, Fotouhi Ghiam A, Vesprini D, Huang X, Commisso K, et al. Circulating miRNAs as non-invasive biomarkers to predict aggressive prostate cancer after radical prostatectomy. J Transl Med. 2019;17(1):173.

174. Liu RSC, Olkhov-Mitsel E, Jeyapala R, Zhao F, Commisso K, Klotz L, et al. Assessment of Serum microRNA Biomarkers to Predict Reclassification of Prostate Cancer in Patients on Active Surveillance. J Urol. 2018;199(6):147581.

175. Bhagirath D, Yang TL, Bucay N, Sekhon K, Majid S, Shahryari V, et al. microRNA-1246 Is an Exosomal Biomarker for Aggressive Prostate Cancer. Cancer Res. 2018;78(7):1833-44

176. Huang X, Yuan T, Liang M, Du M, Xia S, Dittmar R, et al. Exosomal miR-1290 and miR-375 as prognostic markers in castration-resistant prostate cancer. Eur Urol. 2015:67(1):33-41.

177. Jeon J, Olkhov-Mitsel E, Xie H, et al. Temporal Stability and Prognostic Biomarker Potential of the Prostate Cancer Urine miRNA Transcriptome. J Natl Cancer Inst. 2020;112(3):247-55. https://doi.org/10.1093/jnci/djz112.

178. Pellegrini KL, Patil D, Douglas KJS, Lee G, Wehrmeyer K, Torlak M, et al: Detection of prostate cancer-specific transcripts in extracellular vesicles isolated from post-DRE urine. Prostate. 2017;77(9):990-9.

179. Zedan AH, Hansen TF, Assenholt J, Madsen JS, Osther PJS. Circulating miRNAs in localized/locally advanced prostate cancer patients after radical prostatectomy and radiotherapy. Prostate. 2019:79(4):425-32.

180. Sun Y, Hawkins PG, Bi N, Dess RT, Tewari M, Hearn JWD, et al. Serum MicroRNA Signature Predicts Response to High-Dose Radiation Therapy in Locally Advanced Non-Small Cell Lung Cancer. Int J Radiat Oncol Biol Phys. 2018:100(1):107-14.

181. Lin H-M, Castillo L, Mahon KL, Chiam K, Lee BY, Nguyen Q, et al. Circulating microRNAs are associated with docetaxel chemotherapy outcome in castration-resistant prostate cancer. Br J Cancer. 2014;110(10):2462-71.

182. Zhang H-L, Yang L-F, Zhu Y, Yao X-D, Zhang S-L, Dai B, et al. Serum miRNA21: elevated levels in patients with metastatic hormone-refractory prostate cancer and potential predictive factor for the efficacy of docetaxel-based chemotherapy. Prostate. 2011:71(3):326-31.

183. Chen L, Wen Y, Zhang J, Sun W, Lui WWY, Wei Y, et al. Prediction of radiotherapy response with a 5-microRNA signature-based nomogram in head and neck squamous cell carcinoma. Cancer Med. 2018;7(3):726-35.

184. Li A-L, Chung T-S, Chan Y-N, Chen C-L, Lin S-C, Chiang Y-R, et al. microRNA expression pattern as an ancillary prognostic signature for radiotherapy. J Transl Med. 2018;16(1):341.

185. Higgins KA, Saba NF, Shin DM, Beitler JJ, Chen G, Xiao C, et al. Circulating Pre-treatment miRNAs as Potential Biomarkers to Predict Radiation Toxicity. Int J Radiat Oncol Biol Phys. 2017;99(2):E596.

186. Mitchell PS, Parkin RK, Kroh EM, Fritz BR, Wyman SK, Pogosova-Agadjanyan EL, et al. Circulating microRNAs as stable blood-based markers for cancer detection. Proc Natl Acad Sci U S A. 2008;105(30):10513-8.

187. Weber JA, Baxter DH, Zhang S, Huang DY, Huang KH, Lee MJ, et al. The microRNA spectrum in 12 body fluids. Clin Chem. 2010;56(11):1733-41.

188. Blondal T, Brunetto MR, Cavallone D, Mikkelsen M, Thorsen M, Mang Y, et al. Genome-Wide Comparison of Next-Generation Sequencing and qPCR Platforms for microRNA Profiling in Serum. Methods Mol Biol Clifton NJ. 2017;1580:21-44.

189. Zeng H, He B, Yi C, Peng J. Liquid biopsies: DNA methylation analyses in circulating cell-free DNA. J Genet Genomics. 2018;45(4):185-92.

190. Kroh EM, Parkin RK, Mitchell PS, Tewari M. Analysis of circulating microRNA biomarkers in plasma and serum using quantitative reverse transcriptionPCR (qRT-PCR). Methods San Diego Calif. 2010;50(4):298-301.

191. Vignard V, Labbé M, Marec N, André-Grégoire G, Jouand N, Fonteneau J-F, et al. MicroRNAs in Tumor Exosomes Drive Immune Escape in Melanoma. Cancer Immunol Res. 2019;canimm(0522):2019.

\section{Publisher's Note}

Springer Nature remains neutral with regard to jurisdictional claims in published maps and institutional affiliations. 